\title{
In situ observation of solidification patterns in diffusive conditions
}

\author{
Silvère Akamatsu \\ Sorbonne Universités, UPMC Univ Paris 06, CNRS UMR 7588, Institut des NanoSciences \\ de Paris, Case courrier 840, 4 place Jussieu, 75252 Paris Cedex 5, France \\ Henri Nguyen-Thi \\ Aix-Marseille University \& CNRS, IM2NP UMR 7334, Campus Saint-Jérôme, Case 142, \\ 13397 Marseille Cedex 20, France
}

\begin{abstract}
We present a review of recent in situ experimentation studies on solidification front patterns and microstructures in alloys. Front-tracking diagnostics and real-time observation methods using high-resolution optical or X-ray imaging devices currently apply to model transparent systems as well as metallic alloys in thin and bulk samples. On a theoretical basis that spans the physics of nonequilibrium pattern formation and materials science, in combination with time-resolved numerical simulations, conclusive results of both fundamentaland applied-science interest have been obtained on major problems relative to multiscale microstructure selection, morphological transitions, and crystallographic effects during single- and multi-phase solidification. We will mainly focus on the dynamics of cellular, dendritic, and eutectic growth patterns in diffusive-growth conditions, that is, in the absence of convection in the liquid. This can be achieved in (semi-)thin samples, or, for bulk solidification, in the reduced-gravity environment of orbiting facilities. A selection of emerging work on, e.g., faceted growth and adaptive control of solidification patterns will furthermore be reported. We conclude by pointing out open questions and new
\end{abstract}

\footnotetext{
* Corresponding author

Email address: akamatsu@insp.jussieu.fr ()
}

Preprint submitted to Acta Materialia

January 5, 2016 
perspectives for future research.

Keywords: in situ experimentation, solidification, microstructures, microgravity, metallurgy, nonlinear physics

\section{Introduction}

The prediction and control of solidification microstructures in alloys actively stimulates abundant laboratory research linking fundamental and applied sciences. The advancement of in situ experimental methods for real-time obser-

5 vation of the propagating solid-liquid interface during solidification is key to this vast scientific enterprise. Solidification microstructures -modulations of chemical composition, regular arrangements of finely dispersed crystal phases, and lattice defect networks in polycrystals- are a trace, left frozen in the bulk solid, imprinted by growth front patterns. In metals, and nonfaceted materials in general, these self-organizing phenomena are essentially determined by the redistribution of heat and chemical species by diffusion -often "assisted" by convection motions in the melt- and by local equilibrium or fast attachment kinetics at the interfaces. The dynamical origin of solidification microstructures has long been attested [1, 2, 3, and their complexity more and more clearly revealed over time by metallurgical studies, but a consistent nonlinear-physics approach of nonequilibrium pattern formation phenomena has been fostered only in the 1980's [4, 5, 6, 7]. During the last two decades, systematic experimental studies have been undertaken in a coherent theoretical context, implementing high-resolution front-tracking diagnostics and real-time observation methods in polycrystals and multiphase composites on the required time and space scales. In parallel, time-resolved numerical simulations quickly developed [8, 9, 10]. By these combined means, conclusive results have been obtained with unparalleled accuracy on major questions concerning morphology selection and transition processes, microstructural defects, and crystallographic effects during one- and multi-phase solidification, thus opening up to further prospects on both theoretical and technological levels. 
We present a review of recent experimental results obtained by real-time observation methods during solidification of dilute and eutectic alloys. Major breakthroughs from in situ solidification (shortly speaking) research can be traced back to the implementation, in the 1960s, of thin-sample directional solidification of transparent alloys "that freeze like metals" by Jackson and Hunt [11, 12, and further developments during the 1970-1980 decades [13] (also see Ref. [14]). Since the middle of the 1990's, discoveries have followed an accelerated pace. Real-time observation has been extended to bulk transparent alloys during directional solidification, and, by taking advantage of high-brilliance X-ray facilities, to metallic alloys. For clarification, we will consider situations where perturbing factors coming from gravity- (or capillarity-) driven convection in the liquid were minimised, thus closely approaching the ideal limit of diffusion controlled growth. We also deliberately place ourselves in conditions close to conventional casting, therefore excluding fast solidification from our report. Focus will be put on experimental studies based on directional-solidification methods performed with thin samples, and, for bulk solidification, in reduced-gravity conditions in orbiting facilities. We will highlight the success of a synergic research combining in situ solidification and numerical modelling, which is highly 45 exemplary, and particularly fertile. In these conditions, the morphological stability of dendritic, cellular, and lamellar/rod-eutectic solidification patterns have been carefully tested. Moreover, remarkable growth shapes (doublon, spiral two-phase dendrite) and complex space-time phenomena in drifting and oscillatory patterns have been discovered. The strong history and boundary-condition dependency of extended solidification patterns has been clearly demonstrated. New insights into initial and transient stages, as well as mild instrumental forcing (thermal bias, isotherm curvature) have been gained. Our understanding of the interplay of the solidification dynamics with crystal-lattice defects, and with the crystallographic anisotropy of the solid-liquid and solid-solid interfaces 55 involved in the solidification process is also deeply improving. Most of the overviewed studies share in common a general-physics approach of solidification front pattern formation and stability, and are directed towards the unraveling 
of complex aspects of the nonlinear dynamics involved in the formation of solidification microstructures. They also openly keep a tight link with pending questions of great importance in materials science (e.g. columnar vs equiaxed growth, polycrystal and eutectic-grain textures), from which they are obviously inspired, and on which they cast new light. This corpus of experimental findings is of essential help for validating fundamental models and existing predictive codes. It should moreover provide a new basis for optimising the modelisation of natural and industrial solidification processes, during which fluid flow in the liquid and plastic deformation in the solid are involved.

This review is structured as follows. We briefly present the general context (diffusion controlled growth experiments in thin samples and in microgravity) in Section 2. In Section 3, novel observation methods are briefly presented.

70 The main results are presented in the following order. Section 4 is dedicated to dendritic and cellular patterns in dilute alloys. It is divided into three parts. In Section 4.1 (thin-sample solidification), particular emphasis will be put on the role of interfacial anisotropy in the stability of dendritic (Section 4.1.1) and cellular (Section 4.1.2 patterns. The dynamics of grain-boundary grooves (Section

75 4.1.3, and a novel method developed for a local adaptive control of solidification patterns (Section 4.1.4) will be briefly presented. In Section 4.2, we will focus on bulk solidification in nearly diffusive conditions, that is, in practice, in microgravity $(\mu \mathrm{g})$ facilities. After a brief report on pioneering work (Section 4.2.1), optical observations of cellular and dendritic arrays in transparent alloys (Sec-

80 tion 4.2.2 will be described. The presentation of X-ray radiography studies of columnar and equiaxed growth regimes in metallic samples (Section 4.2.3) opens up to a brief discussion on possible mechanisms (including convection or advection motions in the interdendritic liquid) at play in dendrite-arm fragmentation processes. In Section 4.3, some prospective studies on faceted growth -in par85 ticular, polycrystalline silicon- will be mentioned. Eutectic growth is presented in Section 5. It will begin with thin-sample directional solidification of binary eutectics (morphology diagram; Section 5.1.1) and ternary eutectic alloys (spiral two-phase dendrite, three-phase patterns; Section 5.1.2. We present new in- 
sight into the problem of the formation of eutectic grains (interphase boundary anisotropy) in Section 5.2. Finally, complex features of lamellar and rod-like eutectic growth in bulk transparent samples will be presented in Section 5.3 . Conclusions and perspectives are proposed in the last section.

\section{General context}

Nonfaceted crystal growth from the melt is practically equivalent to diffusion controlled growth. [The theory of the solidification problem has been presented in many textbooks (e.g. Ref. [9]).] Similar solidification pattern formation phenomena are observed in nonfaceted alloys, independently of their chemical nature -those include metals, salts [15], rare gases [16, 17] and some organic compounds with a low melting entropy (Jackson criterion) [11]. In simple cases, heat is rapidly evacuated ("frozen temperature field"), and solute diffusion in the solid negligible. The solidification dynamics is then dominated by the diffusion of chemical species in the liquid. For growth rates in an ordinary range for bulk solidification $\left(<<1 \mathrm{mms}^{-1}\right)$, attachment kinetics at the solid-liquid interface can most often be assumed to be instantaneous. Therefore, in addition to solute diffusion in the liquid, the free-boundary problem includes mass conservation at the moving solid-liquid interface (Stefan condition) and local equilibrium at the interface (and at trijunctions for coupled, multiphase growth). We recall the definition of the diffusion length $l_{d}=D / V$ (with $D$ the solute diffusion coefficient in the liquid for a binary alloy, and $V$ the propagation velocity of the solidification front), which measures the strength of the diffusive couplings close to the interface $\left(l_{d}\right.$ typically varies within $\left.10-1000 \mu \mathrm{m}\right)$. The capillary length $d_{0}$ is proportional to the solid-liquid surface tension $\gamma$, and is associated to curvature effects $\left(d_{0}\right.$ does not exceed a few $\left.10 \mathrm{~nm}\right)$. Characteristic scaling lengths of, e.g., cellular and eutectic patterns, are nonlinear combinations of $l_{d}$ 115 and $d_{0}$.

Explicit theoretical tracking of the nonlinear, multiscale solidification problem can be performed only for a few particularly simple situations (steady-state 
patterns, short transients). Paradigmatic cases are the Mullins-Sekerka (MS) analysis of the cellular instability of the planar front in dilute alloys [3], the free dendrite at small undercooling [7], and the Jackson-Hunt theory of lamellar eutectics [12]. For more realistic phenomena, time-resolved numerical simulations are required. Front-tracking methods (sharp interface) [18], and, more frequently at present, phase-field (PF) models are of current use [8, 10]. On space scales approaching casting conditions, scale-bridging models [19, 20, 21, 22] and numerical automata (e.g. CAFE, Cellular Automaton-Finite Element [23, 24]) for polycrystal growth are progressively improved. For quantitative purposes, special attention is also brought to high-accuracy thermophysical measurements [25. The thus obtained results serve as quantitative references/benchmark data for realistic integrated computational materials engineering (ICME) programs using multiscale numerical simulations. In this overview, key numerical results will be mentioned in correspondence with experimental studies.

In normal gravity, thermosolutal convection during solidification is induced by built-in constitutional and thermal gradients, and/or by instrumental imperfections (tilted, nonplanar isotherms). The flows in the liquid modify the diffusion layer, and generally prevent the formation of steady solidification patterns with uniform features. These effects can be avoided in samples with a reduced size (at least in one dimension). In very thin, flat samples of thickness in the $10 \mu \mathrm{m}$ range, diffusive growth occurs in an essentially two-dimensional (2D) geometry, with good thermal control. Solidification experiments with weak convection can be performed in samples of thickness in the $100 \mu \mathrm{m}$ range (and also in cylindrical capillaries of inner diameter of less than $1 \mathrm{~mm}$ for metallic alloys [26]). Suppressing convection motions in bulk samples (also referred to as three-dimensional, or 3D, samples) during solidification is a much more challenging task. Vanishing convective mass transport can be achieved in an orbiting microgravity facility, independently of alloy composition and container shape. Considering the large characteristic times of diffusion controlled growth, long-duration microgravity conditions with reduced parasitic accelerations (gjitters) are required. Accordingly, dedicated in situ solidification setups have 
been installed on board of various space orbiting platforms (e.g. the now retired space shuttles or MIR station, or Foton satellites) and more recently on the International Space Station (ISS) or sounding rocket (MASER), under the cooperative control of several space agencies in the world [27. We will present below several successful real-time solidification experiments under microgravity, in bulk transparent (visible-light optical diagnostics) and metallic (microfocus X-ray) alloys. Perturbing effects induced by gravity during solidification investigated by mean of synchrotron X-ray radiography have been presented in many previous publications (for a review, see, e.g. Ref. [28]).

\section{Real-time imaging methods}

\subsection{Directional solidification}

Most laboratory investigations of solidification pattern formation are carried out in the presence of a thermal gradient. In directional solidification (DS) properly speaking, crystal growth is performed by pulling the sample at constant velocity $V$ in a fixed temperature gradient $G$ (axis $\mathbf{z}$ ) between two thermally regulated blocks (Bridgman method). Ordinary $G$ values fall in the $10-100 \mathrm{~K} \mathrm{~cm}^{-1}$ range, and $V$ is commonly varied between 0.01 and $100 \mu \mathrm{ms}^{-1}$, depending on the problem under consideration. Directional solidification allows for the formation of steady-state patterns over large time and space scales after relatively short transients. Periodic patterns are characterised by the spatial period or "spacing" $\lambda$. In steady-state conditions, the solidification front follows, in average, a given isotherm parallel to the xy plane, and perpendicular to $\mathbf{z}$. Deviations from this ideal situation will be reported below. An alternative way to achieve DS is to decrease the temperatures of both hot and cold zones of the furnace at a given rate by keeping the sample fixed. There is no well-defined steady-state in that case (see columnar growth during casting), but

175 this protocol permits efficient (and easier) image processing when using in situ X-ray radiography [29]. 
A basic DS protocol consists of: (i) partial directional melting, and solidliquid equilibration at rest $(V=0)$; (ii) pulling at given $V$ until a steady state is reached; (iii) morphological-stability tests upon successive up- or downward

\subsubsection{Model alloys}

For real-time observation, DS experiments are most commonly carried out with transparent organic alloys (molecular "plastic" crystals [37]), in particular alloys based on succinonitrile (SCN) [13, 38, 39, 40, 41, 42, 43, 44] or carbontetrabromide $\left(\mathrm{CBr}_{4}\right)$ [12, 45, 46] (also see liquid-crystal systems [34, 35, 47, pivalic acid [48, and $\mathrm{NH}_{4} \mathrm{Br}$ water solutions [32]). For quantitative purposes, 
purified compounds with impurity levels of a few $10^{-2}$ mol\% or less are used. Trace impurities (in particular, residual gases) with a low partition coefficient slowly accumulating at the growth front can induce substantial perturbations diagram, and impurity amount), in particular by quantitatively analysing the initial transient [46, 51, 54]. In a dilute-alloy sample maintained at rest $(V=0)$, the unmelted solid equilibrates with the liquid at the liquidus temperature $T^{l}$. In steady-state $(V \neq 0)$, the planar front is at the temperature of the solidus $T^{s}$ ${ }_{230}\left(<T^{l}\right)$. During the solute redistribution transient, the interface recoils over a distance $l_{t}=\Delta T_{0} / G\left(\Delta T_{0}=T^{l}-T^{s}\right)$ in the thermal gradient [55]. A theoretical analysis of this transient in a quasistatic approximation was made by Warren and Langer [56. In bulk samples, the release of latent heat at the interface cannot be neglected, even at low velocities [57]. 


\subsubsection{Bulk-sample directional solidification}

In recent years, much progress has been made in real-time imaging of solidification front patterns in bulk transparent samples. Two major issues must be addressed. The first one concerns the detrimental effects of convection motions in the liquid. This justifies, as explained above, the use of microgravity facilities. The second difficulty is related to the formation of good images of the solid-liquid surface in a top view with sharp contrast and suitable spatial resolution. Two distinct methods developed for eutectic alloys on the one hand, and cellular and dendritic patterns in dilute alloys on the other hand will be shortly presented.

The DIRSOL instrument (Fig. 19) has been developed for real-time observation of eutectic solidification in (semi-)bulk samples of transparent alloys [58. The technical characteristics of both the DS bench $\left(G \approx 100 \mathrm{Kcm}^{-1}\right.$; $V=0.01-10 \mu \mathrm{ms}^{-1}$ ) and the (flat-wall) cartridges are similar to those of thinsample setups, but the inner thickness of the samples ranges between 300 and $500 \mu m$ (much larger than the interphase spacing in eutectic microstructures, which typically falls in the $10 \mu m$ range). Real-time observation is performed with a long-distance microscope that focusses the solid-liquid interface in an oblique direction $\left(40-50^{\circ}\right)$ relative to the solidification axis, through the liquid and a glass wall (non-invasive method). Illumination is applied in an oblique way as well, through the solid. A low numerical aperture is used to select light rays from one of the two eutectic phases only, and to form a dark-field image with a nearly white-and-black contrast between the two solids at the interface (effective optical resolution of about $3 \mu \mathrm{m}$ ). Two conditions must be met for achieving a clear picture of the whole front despite the inclination of the microscope: (i) the viewing angle must be such that the image plane of the microscope coincides with the image of the solidification front (this optimum angle depends on the refractive index of the liquid; it also maximises the image aspect ratio); (ii) the aperture of the microscope must be low enough to limit the astigmatism inherent in optical devices with planar diopters. Thermosolutal convection can 
be avoided (vertical DS setup) for alloys of near-eutectic concentration. Representative images of lamellar $\left(\mathrm{CBr}_{4}-\mathrm{C}_{2} \mathrm{Cl}_{6}\right)$ and rod-like (SCN-DC) patterns are shown in Figs. 1p and 1, respectively. More detailed results are presented in Section 5.3. A multi-user apparatus (called "Transparent Alloys") based on the same optical method as DIRSOL, and dedicated to in situ solidification in microgravity (ISS), is currently being developed by the European Space Agency (ESA) [59]. Recently, another original observation method has been developed by Witusiewicz et al [60, 61]: the image of the solidification front is reflected by a small mirror immersed in the liquid inside the sample (and inclined by $45^{\circ}$ with respect to the solidification $\mathbf{z}$ ), and focused onto a long-distance microscope.

The Directional Solidification Insert (DSI) of the multi-user DECLIC (DEvice for the study of Critical LIquids and Crystallisation) facility has been developed by the French Space Agency (CNES), and installed on the ISS in August 2009 as part of a joint NASA/CNES microgravity-research program 62]. Based on a similar principle as the pioneering MOMO apparatus 63, DSI is dedicated to real-time observation of DS front patterns in bulk samples of dilute transparent alloys (Fig. 2). The samples are 10-cm long cylindric fused-quartz tubes with an inner diameter of $1 \mathrm{~cm}$, filled with a dilute SCN-based alloy (the intercell or dendrite spacing usually falls in the $100 \mu \mathrm{m}$ range). This makes possible long-time solidification of extended 3D patterns over several centimetres in wellestablished steady state, free of noticeable finite-size effects $\left(G=10-30 \mathrm{~K} \mathrm{~cm}^{-1}\right.$; $\left.V=0.1-30 \mu \mathrm{ms}^{-1}\right)$. A volume-compensation system accommodates density variations associated to phase changes in the sample. An endoscopic optics is immersed in the liquid and automatically focuses the solidification front in a top view. The light source is placed at the cold end of the sample, just behind an optically flat glass window. In the main observation mode, axial observation of the solidification pattern takes advantage of the complete transparency of the medium. The light propagates through the solid, and is refracted when passing through the (patterned) solid-liquid interface. The image of the interface is formed on a grey-level CCD camera. In addition, a Mach-Zehnder interferometer is set along the visualisation axis. Interferograms at the solid-liquid interface 


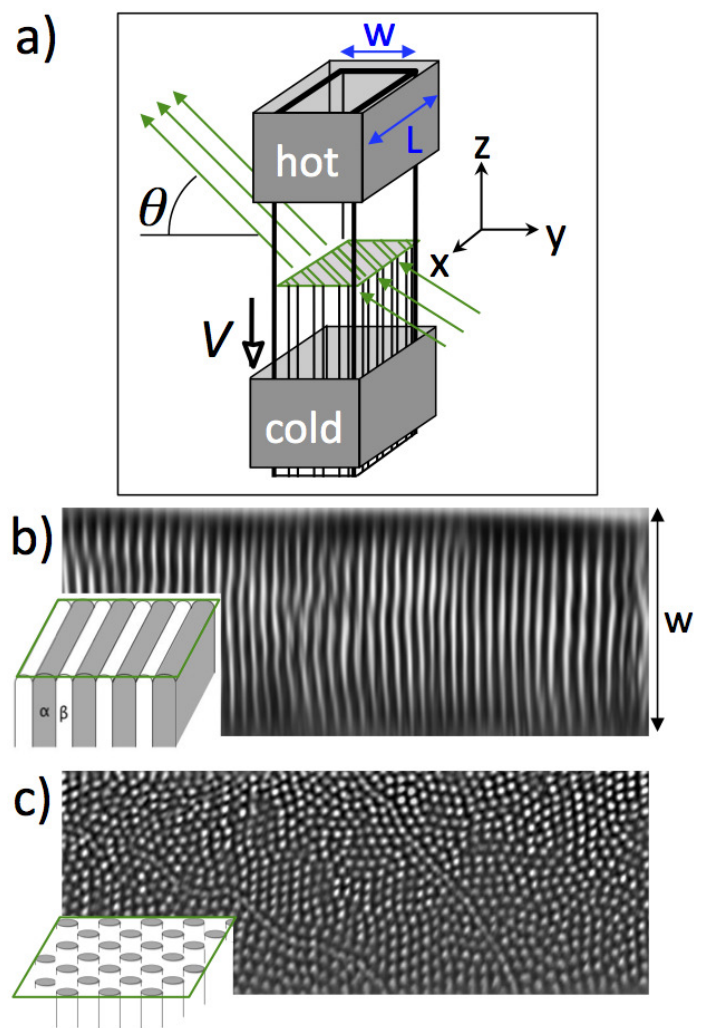

Figure 1: a) Principle of the DIRSOL apparatus: oblique observation (angle $\theta$ ) of the solidliquid interface during DS of a transparent eutectic alloy. z: direction of the thermal gradient $G$ and of pulling (velocity $V$ ). y: normal to the glass walls. The optical axis lies in the yz plane. $w$ : thickness of the sample. $L$ : lateral width of the sample $(L>>w)$. b) Lamellar pattern in a $w=350-\mu m$ thick sample of near-eutectic $\mathrm{CBr}_{4}-\mathrm{C}_{2} \mathrm{Cl}_{6}$ alloy $\left(V=0.37 \mu m s^{-1}\right)$. Bright (dark) lamellae: $\alpha(\beta)$ phase. c) Rod-like pattern in a 350- $\mu \mathrm{m}$ sample of a eutectic succinonitrile-d,camphor alloy $\left(V=0.035 \mu \mathrm{ms}^{-1}\right)$. Bright spots: DC fibers (the SCN matrix is dark). The images have been rescaled numerically to 1:1 aspect ratio. 
provide a precise 3D image (contour lines) of the growth shape 64]. An external optics for side-view observation also gives useful information on the average shape of the interface along the thermal axis. The operator scientists have the possibility to follow and remotely control the experiments by tele-science in near real-time conditions. Six runs of $2-3$ weeks each were performed from April 2010 to April 2011. Two solidification runs have been performed on ground with the same control parameters as in the $\mu \mathrm{g}$ experiments. Some of the results are presented in Section 4.2 .2 .

\subsection{Metallic alloys}

Real-time observation of the solidification process in non-transparent materials (metals and semiconductors) has been a critical issue for a long time. Standard investigation techniques, such as quenching or decanting, do not provide the interface evolution over time in $3 \mathrm{D}$, but gives only a "frozen" picture of the solid microstructure. A first attempt to follow in situ the interface behaviour during solidification was made in a seminal microgravity study of timedependent solidification phenomena in large metallic samples of $\mathrm{Sn}-\mathrm{Bi}$ alloys (Mephisto apparatus) [65, 66]. In that program [which was conducted in the now retired shuttle, United States Microgravity Payload (USMP) missions] a sophisticated DS furnace was used to process three samples in parallel, and gain complementary information about alloy composition, actual growth velocity and temperature gradient at the interface. The most salient feature was the implementation of a real-time thermo-electric (Seebeck) diagnostic between two solid-liquid interfaces, one providing a fixed temperature reference, while the other was allowed to move at controlled $V$. A strong Seebeck signal was obtained with $\mathrm{Sn}$ rich alloys doped with Bi (1-mol\% range). In planar-front conditions, the Seebeck signal is directly proportional to the interface undercooling. The analysis was more complicated in cellular or dendritic configurations. Other experimental methods for front tracking in metallic alloys include: (i) side-view observations of the solidification front position in cylindrical metallic samples 


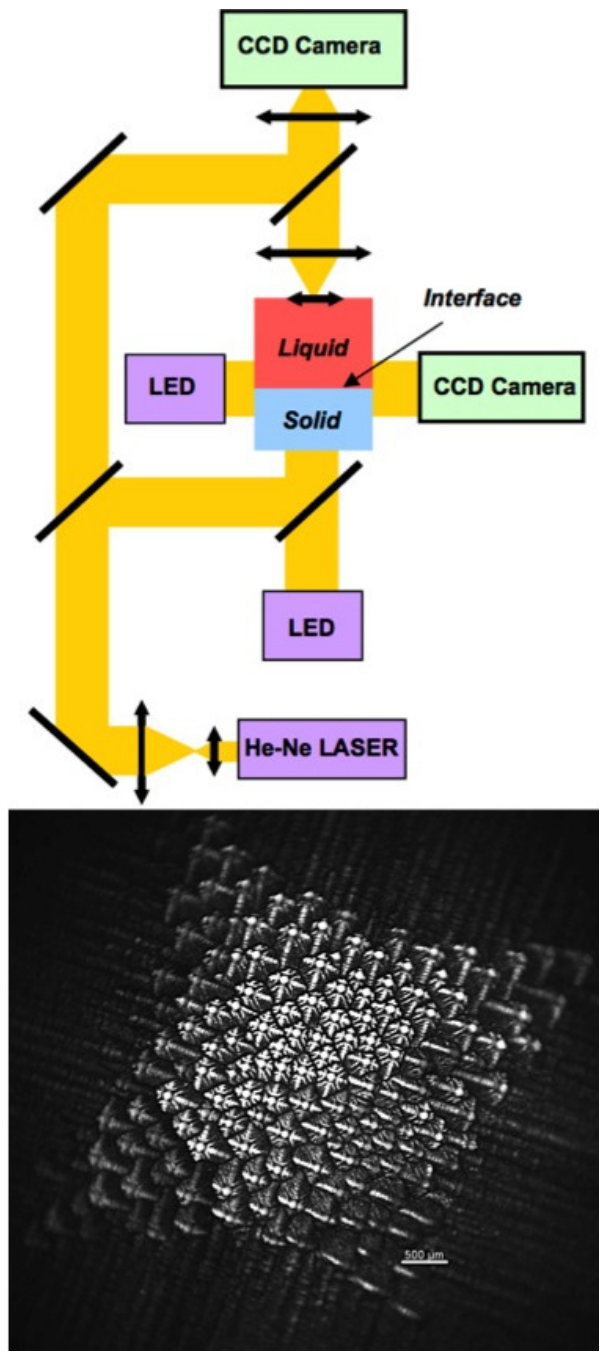

Figure 2: Top: principle of the optical diagnostics of the DECLIC-DSI apparatus; yellow lines: optical paths. CCD cameras: top- and side-view imaging. He-Ne laser: interferometry imaging. Colour online. Bottom: dendritic array observed with DECLIC-DSI on board of the ISS (SCN-0.24wt\% camphor; $V=30 \mu \mathrm{ms}^{-1} ; G=28 \mathrm{Kcm}^{-1}$ ). White bar: $500 \mu \mathrm{m}$. Courtesy N. Bergeon. 
ultrasonic detection (see, e.g., Ref [68]). Those techniques are, however, limited to global information on the solidification front dynamics, and do not give reliable access to microstructural features.

This difficulty could be partly circumvented in alloys, in which the solidliquid interface is strongly sensitive to a thermoelectric effect (Peltier interface demarcation technique). A short-current pulse of high intensity is transmitted through the solidifying sample, thus leaving a thin frozen-in compositional trace in the solid, which more or less delineates a contour of the solid-liquid interface. A time sequence of electric pulses thus results in a spatial series of compositional marking, which, after proper etching of a longitudinal section, reveals the interface position and shape at successive times during growth [69. This technique has proven its capabilities for the study of faceted growth of Bi-Sb alloys [70].

For deeper insight into metallic-alloy solidification, a major breakthrough was the use of high-intensity X-ray sources. Indeed, the features (intense and coherent beams) associated with modern synchrotron radiation (SR) resulted in a substantial extension of X-ray imaging capabilities to high (spatial and temporal) resolution, and 3D tomographic images. This allows one to gain key information on crystal growth-related phenomena that was not available hitherto. Synchrotron-radiation X-ray imaging techniques can be basically divided 345 into two main types:

1-Bragg diffraction imaging, such as polychromatic (white-beam) X-ray topography, allows for a characterisation of the long-range strain field around crystallographic defects, as well as weak distortions in bulk crystals [71, 72, 73, 74, 75]. X-ray topography has been widely used for the study of the interplay between crystal defects (dislocations, twins, stacking faults, inclusions or precipitates) and crystal growth mechanisms [76. In brief, when a crystal fulfils the Bragg conditions for some of the wavelength(s) of the white beam, part of the incoming light is diffracted in specific directions. Crystal-lattice defects are revealed by intensity variations associated to local mechanical distortions (lattice parameter variation or lattice rotation) of the crystal. In practice, several diffracted spots can be recorded on the same image, and each spot has the shape of a diffracting 
crystal grain. The analysis of the different diffraction spots for a given crystal gives complementary information about strains and misorientations in the solidification microstructure [74, 77. The high SR flux makes it possible to record simultaneously several diffracted images (1-s exposure time) on the same detector with a high sensitivity $\left(<10^{-6}-10^{-3}\right)$ and a spatial resolution in the micrometer range, and to use relatively large samples (a few $\mathrm{cm}^{2} \times 0.1 \mathrm{~cm}$ ). 2-Radiography techniques are based on the local changes in the amplitude of a transmitted X-ray beam due to differential absorption by an inhomogeneous sample [78, 79, 80, 81]. (Fast and ultra-fast tomography for 3D imaging in small cylindrical samples has hardly been used for in situ study of the solidification dynamics in proper; it will not be addressed in this review [82, 83, 84, 85.) Since the early 2000s, high-brilliance SR, combined with the most advanced Xray optics and cameras, makes it possible to capture real-time video sequences of flat (thickness of $150-200 \mu m$ ) metallic alloys during DS. The image contrast results firstly from the segregation of chemical species (see, e.g., $\mathrm{Al}-\mathrm{Cu}$ ) and secondly from density difference between the solid and the liquid (see, e.g., Al-Si, and pure $\mathrm{Si}$ ). The principles of SR-based radiographic acquisition methods can be simply recalled as follows. A monochromatic X-ray beam illuminates the sample. The transmitted beam is collected by a $2 \mathrm{D}$ detector (basically a CCD camera equipped with a high resolution scintillator) behind the sample. Radiographs with image resolution down to $100 \mathrm{~nm}$ at frame rates of $20 \mathrm{~Hz}$ could be obtained in the best conditions. Breakthrough observations were obtained on columnar growth [86], columnar-to-equiaxed transition [87, 88, dendrite fragmentation [89, 90] (see Section 4.2.3), bending of secondary arms [91, equiaxed growth 92, and the influence of convection during planar-front solidification 93. (details on DS devices adapted to SR facilities can be found in those references). Globally, SR-imaging studies pinpointed the strong influence of gravity (convection and buoyancy forces) on the solidification microstructures in normal 385 gravity environment.

Recent developments of the microfocus X-ray technique, along with increasingly powerful X-ray sources and sensitive detectors, have led to vast improve- 
ments in the performance of laboratory radiography setups (see, e.g., Ref. 94]). In the framework of an ESA project, a novel microfocus X-ray radiography facility dedicated to the study of the solidification of Al-based alloys has been developed, and successfully utilised during MASER-12 sounding rocket campaign [95, and parabolic flight [96]. This compact facility, called XRMON-GF (X-ray MONitoring of solidification process - Gradient Furnace), comprises a Bridgman furnace and an X-ray imaging device. The latter consists of a specific microfocus X-ray tube, with a $3 \mu \mathrm{m}$ focal spot (Viscom AG, Germany; in cooperation with DLR, German Aerospace Center), and a digital camera system (Vosskuhler $11000)$ with a CCD sensor $\left(24 \times 36 \mathrm{~mm}^{2}\right)$ adapted for X-ray usage 95. Images (2048x1334 pixels) can be captured at a rate up to $6 \mathrm{~Hz}$. Experiments have been performed with adequate flux to capture at $2 \mathrm{~Hz}$ during MASER-12 mission. While synchrotron sources mostly provide parallel beams, a microfocus source delivers a cone-shaped beam, and permits an image magnification up to a factor 15 , depending on the source-to-sample and source-to-detector distances. In the MASER-12 experiment, a factor 5 for the image magnification was used to enable one to analyse the dynamics of the whole solidification microstructure of the sample. A similar apparatus has been very recently developed in parallel by the german space agency DLR (Deutsches Zentrum für Luft- und Raumfahrt), which is mainly dedicated to the study of equiaxed microstructure evolution in nearly isothermal conditions in thin metallic samples [97. This newly developed apparatus has not been used in microgravity environment up to now.

\section{Dendrites and cells}

\subsection{Purely diffusive conditions: thin samples}

\subsubsection{Dendritic and seaweed patterns}

The dendrite is the most prevalent morphology of diffusion controlled crystal growth in metallic and nonfaceted alloys. Complex microstructural features of great practical impact such as microsegregation, intermetallic precipitation, rheology of the mushy zone and polycrystal textures are largely determined by 
the characteristic size distribution of dendritic structures. A dendrite is a fingerlike, single-crystal growth shape, which propagates at constant velocity $V$ along a particular (high-symmetry) crystal axis. The overall profile of a steady-state dendrite can be approximated, for convenience, by a paraboloid near the tip (tip radius of curvature $\rho$ ), but the detailed shape is, in fact, rather complex, and depends on interfacial-anisotropy parameters. In addition, secondary branching occurring at a distance at the rear of the tip is responsible for the typical treelike aspect of the dendrite. The theoretical analysis of the dendrite problem is ${ }_{425}$ a long story. It started in the late 1940's with the Ivantsov theory of the needle crystal [98, and was completed about 40 years later, when a self-consistent solution of the problem with finite capillarity could eventually be found. A "microsolvability" condition was obtained, which states that the selection parameter $\sigma^{*}=d_{0} D\left(\rho^{2} V\right)^{-1}$ is a constant of the material, and depends on the anisotropy of the solid-liquid surface tension [6, 7, 99. Numerical simulations have essentially confirmed this theoretical scheme [100, 101].

Interfacial anisotropy designates the dependence of the free energy $\gamma$ of the considered interface on its inclination with respect to the crystal lattice. This crystallographic anisotropy is determined on an atomic scale, and naturally respects the symmetries of the crystal (see 102, 103 and refs. therein). For some applications, it is convenient to refer to the polar representation of the anisotropy function $\gamma(\hat{\mathrm{n}})$ ( $\gamma$-plot), where $\hat{\mathrm{n}}$ is the normal unit vector of the interface (see, e.g., Ref. [104]). In a nonfaceted system, solid-liquid anisotropy coefficients do not exceed a few percents, and are difficult to measure in situ $440 \quad 13,33,103,105$.

An experimental demonstration of the dependency of dendritic growth on crystallographic anisotropy has been brought by the discovery of the so-called seaweed structure by 2D numerical simulations [106, 107, 108, and thin-DS experiments [52]. The key experimental point is that in very thin samples, solidi445 fication patterns qualitatively depend on the orientation of the growing crystal with respect to the solidification device: the effective $2 \mathrm{D}$ anisotropy function is given by the cross-section of the 3D $\gamma$-plot of the solid-liquid interface by the 
sample plane. In Ref. [52], axial dendrites were observed when a [100] axis of the bcc crystal was aligned with the main growth axis. In a first approximation, the 2D anisotropy was of the standard $\cos 4 \theta$ form (also see Refs. [38, 41, 109]). In contrast, by selecting a crystal with a (three-fold symmetry) [111] axis perpendicular to the sample plane, dendritic patterns were not observed, but were replaced by unsteady seaweed structures (Fig. [3a) [52, 110, 111]. Close to such an orientation, the fourfold anisotropy vanishes, and the $2 \mathrm{D}$ system is essentially isotropic (assuming that anisotropy components of higher order are negligible). Fundamentally, below a certain anisotropy level, the ordinary dendrite is replaced by a split-dendrite growth shape called doublon (two mirrorimage asymmetric fingers separated by a thin liquid channel; inset I2 in Fig. 3 a). The morphological features of the doublon are uniquely determined at given control parameters, like those of the standard dendrite, except that its growth direction is free, hence the unsteadiness of seaweed patterns. Steady doublons can be stabilised by a small anisotropy (inset I1 in Fig. 3a), and coexist with dendrites. Doublon-like shapes have been observed in 3D, at least transitorily, during isotherm growth 112 and in DS (Fig. 3b). The formation of twinned doublons (rather than dendrites) could also contribute to the formation of "feathery" microstructures in aluminium alloys [113].

Some more complicated dendritic-growth phenomena in cubic crystals cannot be explained by considering a single fourfold component in the $\gamma$-plot (see, e.g., Ref. [114]). In particular, changes in dendritic-growth directions and morphologies have been observed as a function of the undercooling in transparent systems [115, and of the concentration in Al-Zn alloys (ex situ observations) [116]. Plausible explanations have been proposed in both cases (competition between kinetic and capillary effects in the first case [117], and a variation of the $\gamma$-plot as a function of the $\mathrm{Zn}$ concentration in the second), but our under475 standing remains incomplete. Further progress can be expected due to the development of atomic-scale simulations for calculating the solid-liquid surface free energy and its anisotropy [102, 118. The calculated $\gamma$-plot (and the anisotropy of the kinetic coefficient) of pure nickel could be included in phase-field simula- 

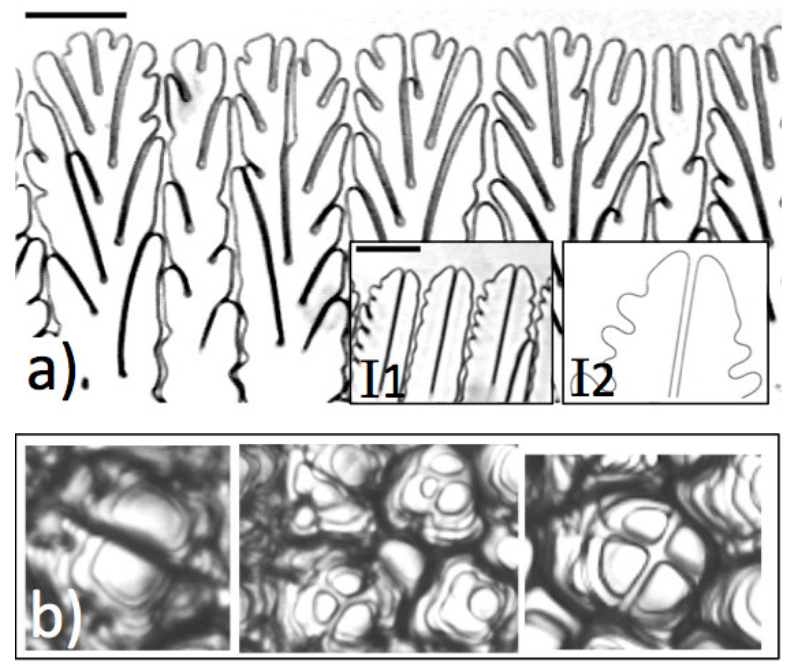

Figure 3: a) Seaweed pattern during thin-DS of a transparent $\left(\mathrm{CBr}_{4}-8 \mathrm{~mol}_{0} \mathrm{C}_{2} \mathrm{Cl}_{6}\right)$ alloy $\left(V=20 \mu \mathrm{ms}^{-1} ; G=110 \mathrm{Kcm}^{-1}\right)$. A [111] axis of the crystal was nearly perpendicular to the sample plane. The growth direction (z axis) is vertical. Insets: Stable doublons in a $\mathrm{CBr}_{4}{ }^{-}$ $4 \mathrm{~mol} \% \mathrm{C}_{2} \mathrm{Cl}_{6}$ alloy (I1), and in a numerical simulation (I2; courtesy T. Ihle). Bars: $100 \mu \mathrm{m}$. For details, see Ref. 52. b) Transient (3D) doublons, triplons and quadruplons observed in top view during a bulk-DS experiment in DSI-DECLIC (N. Bergeon). 
tions, which were compared to ex situ metallographs [119]. Systematic studies combining molecular dynamics calculations of the $\gamma$-plot, phase-field modelling and in situ experiments with full information on the crystal orientation are still lacking, to the best of our knowledge.

In DS, the growth of dendritic arrays is affected by the thermal gradient and the diffusive coupling between neighbouring dendrites [120, 121. Special attention has been brought to tilted-dendrite patterns in (cubic) crystals such that the [100] axis (or its projection in the sample plane) is inclined, that is, the direction of a minimum of $\gamma$ in the $\mathbf{x z}$ plane makes an angle $\theta_{0}$ from $\mathbf{z}$. The dendrite tilt angle $\theta$ is then systematically smaller than $\theta_{0}$, increases when $V$ or the dendritic spacing $\lambda$ increase, but is quite insensitive to $G$. In fact, $\theta$ is found to depend on the sole quantity $P_{\lambda}=\lambda / l_{d}=\lambda V / D$, independently of the thermal gradient $G$, and tends to $\theta_{0}$ for, say, $P_{\lambda}>10$ (Fig. 44 [122]. This behaviour has been observed in various compounds [123], and confirmed numerically [122, 124, 125. Empirical scaling laws have been proposed in order to account for the influence of sidebranching at large $P_{\lambda}$ values 123. For particular crystal orientations such that two maxima of $\gamma$ point more or less symmetrically about $\mathbf{z}$, unsteady "degenerate" patterns are observed 52] (also see Refs. [126, 127]), which resemble to, but must not be confused, in principle, with the (vanishing-anisotropy) seaweed patterns. The morphological transition between tilted dendrites and degenerate patterns as a function of the growth rate could be a good indicator of the level of anisotropy, and/or the relative strength of capillary and kinetic anisotropies. The dynamics of tilted-dendrite arrays plays a crucial role during grain growth competition in polycrystals (see, e.g., [125, 128, 129, 130]).

Let us finally briefly consider the (still largely open) problem of dendrite sidebranching [131]. There is a clear consensus about the $\lambda_{s b} \sim \rho$ scaling behaviour of the sidebranch spacing $\lambda_{s b}$ [32, 38, 39]. Other noticeable aspects are: 1-The onset of sidebranching critically depends on the shape of the dendrite [1]. Some observations indicate that dendrites with a "pointed" shape that substantially deviate from a parabola (and plausibly stabilised by a kinetic 


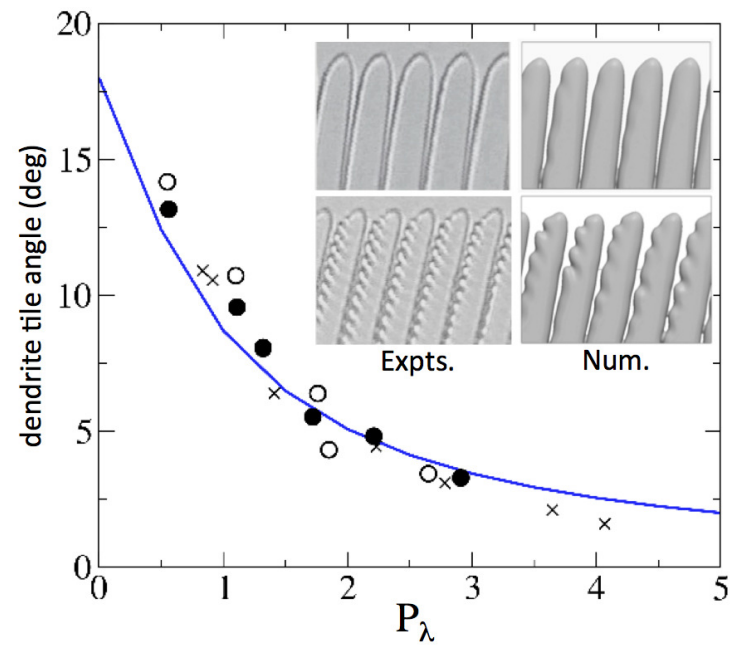

Figure 4: Tilt angle of DS dendrites (measured from the main growth axis $\mathbf{z}$ ) as a function of Péclet number $P_{\lambda}$ (see text). Symbols: experimental (crosses) and 3D numerical (circles) data. Line: empirical scaling-law. Typical experimental and numerical images are shown in the insets. Courtesy A. Pocheau, M. Georgelin and J.M. Debierre -for details, see Ref. 124] and refs. therein.

anisotropy) are less sensitive to sidebranching [52, 132. More importantly, sidebranching of 3D dendrites occurs along the so-called "fins" (see Section 4.2.1). 2-The sidebranching instability is noise-dependent. Under certain conditions (DS), a resonant, synchronised oscillatory instability seems to arise, at least in the form of localised bursts (Fig. 5] [133, 134, thus delivering periodically, and symmetrically spaced secondary branches. Regular sidebranching could be sustained over long times by external excitations ([39, 135]). There is, however, no clear experimental results substantiating a conjectural deterministic dendrite sidebranching process, to the best of our knowledge [136. 3-The growth direction of well-developed secondary branches depends on the crystal anisotropy and the direction of the main dendritic trunk. 4-A strongly nonlinear competition dynamics of sidebranches starts at a relatively short distance from the tip [20, 137]. This coarsening process controls the ternary branching (tail instability) by which a new dendrite can grow and fill in the space between two neighbouring dendrites. 

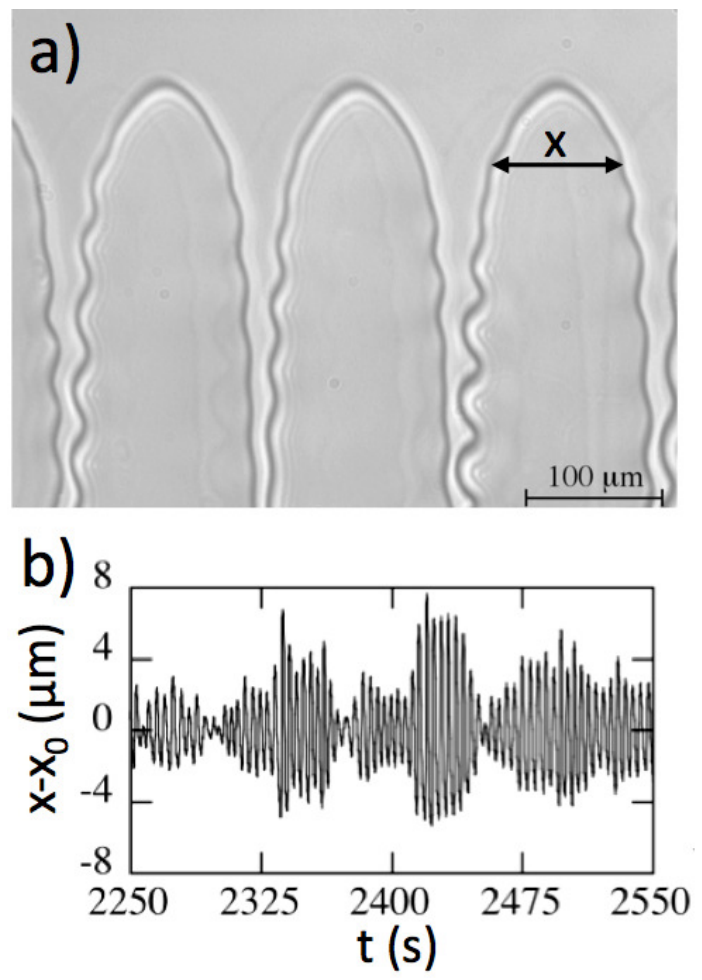

Figure 5: Sidebranching of dendritic fingers during directional solidification of a succinonitrilebased dilute alloy $\left(G=78 \mathrm{Kcm}-1 ; V=15 \mu \mathrm{m}^{-1}\right)$. a) Snapshot of the analysed growth pattern. b) Amplitude $x-x_{0}$ of the fluctuations of the width $x$ of a dendrite in the $\mathbf{x}$ direction $\left(x_{0}\right.$ : average width) at a fixed distance from the tip as a function of time $t$. There is evidence of the occurrence of bursts of 4 to 15 oscillations. Courtesy: A. Pocheau, M. Georgelin (see Ref [133]). 
In directional solidification, dendritic arrays arise from a cellular instability of the planar front above a threshold velocity $V_{c}$ (for an experimental investigation of the early stages of the cellular instability, see Ref. [54]). For $V$ slightly above $V_{c}\left(P_{\lambda}<1\right)$, the system restabilizes into shallow-cell patterns, the dynamics of which is generally strongly nonlinear [50, 138, 139, 140, 141] (for more sinusoid-like cells in a mesomorphic system, see Ref. [47]). From thinDS studies, it was concluded that (i) a finite amount of interfacial anisotropy is needed to stabilise steady cell patterns; (ii) stable axial-cell patterns are observed within a finite interval of intercell spacing values at fixed $V$, which is limited by period-doubling (oscillatory or steady) instabilities [141, 142]; (iii) split-cells (or doublets) can be observed at large cell spacings [142, 143] (for a numerical analysis, see Ref. [144]).

When $V$ is increased, the shape of deep axial cells evolves from a smooth, rounded finger [109, 145] -theoretically analogous to a Saffman-Taylor finger 540 in viscous flow [121] - to a more pointed, dendritic profile with sidebranches. This cell-to-dendrite transition not only depends on $V$ and $G$, but also on the cell spacing $\lambda$, and the interfacial anisotropy. Numerical evidence has been brought that for a relatively large anisotropy, the transition from deep cells to dendritic patterns occurs continuously along a single branch of solutions upon varying $V$ and/or $\lambda$, whereas, for a low anisotropy, the two shapes correspond to two separate branches of solutions [121]. This result can serve as a basis for explaining a hysteresis in $\lambda(V)$ curves measured experimentally upon increasing or decreasing $V$. It is also clear experimentally that axial-dendrite arrays possess a strikingly large stable interval of $\lambda$ [146]. This interval is limited by ternary branching (upper limit), and (at least in 2D) a period-doubling instability that leads to the elimination of one dendrite out of two (lower limit) [147.

\subsubsection{Grain boundaries}

The formation and motion of grain boundaries (GBs) during growth is a major issue in metallurgy. Ordinary, large-misorientation GBs with a large free 
energy are decorated by a thin wetting layer (wet GBs) when put in contact with the liquid [148, and are very mobile in the solid down to temperatures much lower that the melting temperature. In a thermal gradient, wet GBs rapidly migrate and reach an equilibrium configuration, thus running perpendicular to the solid-liquid interface [149]. Incidentally, the shape analysis of the solid-liquid meniscus (groove) at the intersect with a GB is a well-known method for estimating interfacial free energies [150, 151, 152]. In contrast to ordinary GBs, subboundaries $(\mathrm{SBs})$ with a low interfacial energy are practically immobile in the solid. Some insight into the question of the formation of SBs during growth above the cellular threshold was provided by a pioneering study by Grange et al. 71] (synchrotron X-ray topography), who were able to visualise the organisation of (bunches of) dislocations in the solid associated to the solidification of metallic alloys. During deep-cell growth, dislocations remain attached at the triple contact line between the liquid, the crystal and the container wall. They grow passively, until they arrange themselves (possibly under the effect of a thermal stress) and form a SB. This phenomenon can repeat itself during growth, and cause a progressive polygonization of the initial single crystal.

Dynamic polygonization also occurs during slow growth (planar front) [153]. A theoretical analysis of this phenomenon has been made on the basis of in situ observations during thin-DS [149]. It predicts that, due to their coupling 575 with the movements of the solidification front precursory to the Mullins-Sekerka instability itself, the characteristic spacing between SBs decreases with $V$ approximately as $V^{-1 / 2}$. Once formed, SBs align onto a low-energy plane, and intersect the solid-liquid interface obliquely. Therefore, SB grooves move laterally during solidification. Finally, there is some indication that, at low velocity, the SB-groove drift is fully determined by the (strong) anisotropy of the SB, but vanishes as $V$ approaches $V_{c}$ due to the interaction of the SB groove with the solute diffusion field in the liquid [154] (also see Section 5.2). 


\subsubsection{Local control}

Active control of solidification microstructures is a challenging subject in engineering metallurgy. For both laboratory and application purposes, attempts to produce regular microstructures over long solidification distances can be made by implementing predefined experimental protocols based on directionalsolidification techniques. Such global-control techniques still remain only partly effective, and poorly reproducible. In contrast, a local adaptive control of solidification structures can be achieved by using real-time, micron-scale perturbations. A method in transparent alloys, first introduced by Qian and Cummins [39], consists of focussing a collection of light (UV or laser) spots in the vicinity of the solid-liquid interface [54, 147]. Heating due to partial light absorption by the liquid modifies the local shape of the thermal field, and slows down the solidification (or melts back the solid) on a $5-50 \mu \mathrm{m}$ scale, depending on the injected power and the focussing optics. During thin-DS, it was possible to impose a "pre-patterning" of a planar interface, and to guide the system toward a cellular pattern of chosen periodicity within the stable range. Periodic arrays of doublet-cell structures have also been obtained for values of the cellular spacing at which they do not spontaneously appear from a MS instability of the planar front, but for which their stability is duly demonstrated experimentally with full agreement with phase-field simulations [143. More specifically, in an experimental and numerical proof-of-concept study [155], a feedback-control scheme was applied to stabilise deep-cell patterns with a (small) spacing outside the natural stability domain, that is, more precisely, below the period-doubling instability threshold mentioned above (Fig. 6). Other possible applications include the space-time control of eutectic growth patterns [156]. Extending such methods to bulk (poly)crystals [157] still remains under prospect.

\subsection{Near-diffusive conditions}

\subsubsection{Pioneering studies in microgravity}

Microgravity experimentation remains an irreplaceable way to study the formation of solidification microstructures in bulk containers in near-diffusive 


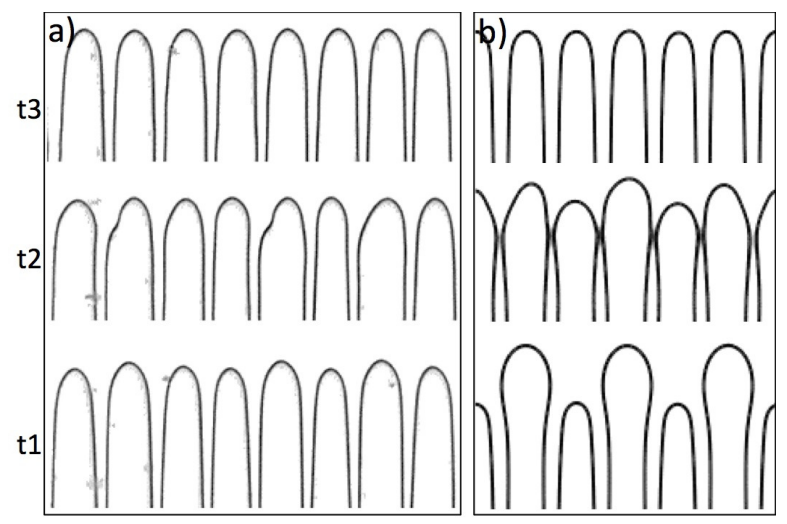

Figure 6: Feedback control of a small-spacing cellular pattern. a) Thin-DS experiment (dilute SCN-coumarin 153 alloy; $\left.V=4.6 \mu \mathrm{ms}^{-1} ; G=10 \mathrm{Kcm}^{-1}\right)$. A numerically addressable device focuses laser spots (not visible) in the liquid just ahead of the cell tips that overhang the average position (local heating). Horizontal dimension: $0.8 \mathrm{~mm}$. b) Phase-field simulation (courtesy A. Karma). Control off (t1): the cell pattern is undergoing a period-doubling instability (elimination of one cell out of two). Control on: transient stage (t2) and stabilised pattern (t3). For details, see Ref. 155.

conditions. By comparison, solidification studies in ordinary laboratory conditions reveal important effects associated to gravity [28. A pioneering, inspiring series of microgravity studies has been carried out by Glicksman and coworkers more than thirty years ago [13, 158]. The Isothermal Dendritic Growth Experiment (IDGE) was developed specifically to test dendritic growth theories by performing measurements with ultrapure succinonitrile (SCN) and pivalic anhydrid acid (PVA) under strictly diffusion-controlled conditions. The IDGE instrument was flown three times (from 1994 to 1997) aboard the space shuttle Columbia at a mean quasi-static acceleration of about $0.7 \times 10^{-6} g_{0}\left(g_{0}:\right.$ normal gravity) [159, 160, 161, 162. This series of experiments provided a huge quantity of experimental documents, showing dendritic solidification at various undercoolings. The dendrite tip velocity $V$ and radius $\rho$ were measured as a function of the imposed undercooling, and a test of the theory was performed by examining the variation of the Péclet number $P=\rho D / V$ as a function of the undercooling. Good repeatability of the experiments was established, bringing the 
first solid evidence of dendritic growth fully governed by heat diffusion in a pure substance. Interestingly, Péclet numbers measured under reduced gravity were substantially different from terrestrial data, and much closer to the theoretical predictions. A slight discrepancy at low undercooling in $\mu$ g experiments was attributed to residual convection in the melt or a finite-size effect [163]. The value of the selection constant $\sigma^{*}$, estimated over a large undercooling range, did not show significative deviation between microgravity and laboratory measurement, but exhibited a slight decrease at large undercooling (note that the analytical scaling theory of dendrite growth was derived under a small-undercooling hypothesis). In brief, while the Ivantsov law is substantially affected by convection motions (and finite-size effects), the $\rho^{2} V=c s t$ scaling law is quite robust, at least in a pure substance, against mild perturbations [36, 164]. This experimental campaign was a first, seminal success for further microgravity science in solidification. (As a complementary approach, mild natural convection effects were probed in dedicated setups [165, 166, 167].)

For completeness, let us also mention some remarkable results obtained in laboratory conditions. A fully 3D morphological study of dendrites growing in rare gases has been performed by Bilgram and coworkers (Fig. 77) [17, 168, 169] (also see [16]). Similar measurements have been done with solutal dendrites in binary alloys (Fig. 7b) [166, 170]. Experimental evidence was given that the basic shape of a 3D dendrite slightly departs from a paraboloid in the tip region. At a larger distance from the tip, a clear change of the basic dendrite morphology 650 is no longer a circle, but exhibits a number of protruding bumps (four as concerns [100] dendrites in cubic crystals), which depends on the symmetry of the crystal and the growth axis. This agrees well with theoretical [171] and numerical predictions [100, 101].

Finally, in a remarkable work by Dupouy and coworkers (post-mortem observations of Al-Cu samples solidified during the D1-Spacelab mission; see Ref. [172]), the difference between space and ground samples showing very different primary spacings and dendritic-array morphologies was thoroughly analysed. This work 

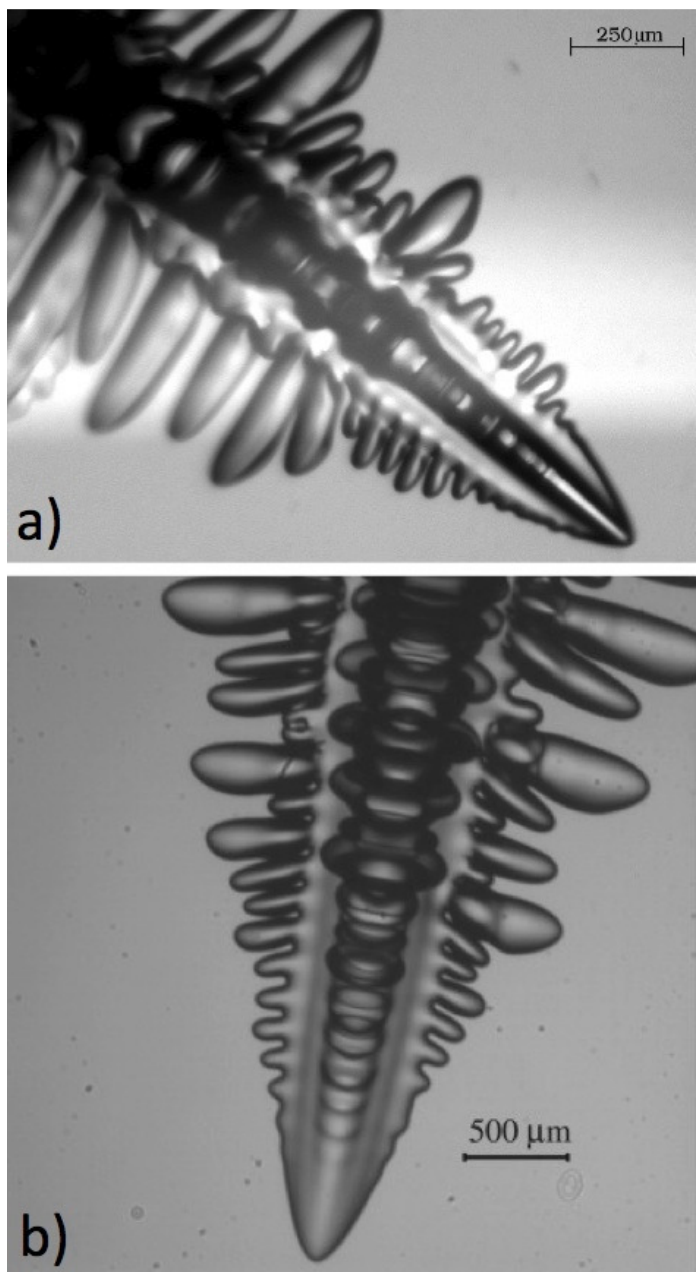

Figure 7: Free-dendrite growth. a) Pure xenon (reprinted from Ref. [168, with permission from EDP Sciences; http://epljournal.edpsciences.org/). b) Succinonitrile-0.0086 mol\%acetone alloy (reprinted from Ref. [170], Copyright 2012, with permission from Elsevier). 
has been further extended to the influence of gravity on eutectic-dendritic and cell-dendrite transitions [173, 174]. More recently, the influence of convection on the columnar-to-equiaxed transition was studied based on microgravity experiments carried out in the Material Science Laboratory (MSL), in the framework of CETSOL (Columnar-to-Equiaxed Transition during SOLidification processing) project of ESA [175]. Further in situ and real-time characterisation of space experiments is still required to deepen our understanding of more complex microstructural transitions and periodic or unsteady phenomena during transient stages or under fluctuating thermal conditions. For this purpose, a new generation of space facilities has been developed, which integrate advanced in situ diagnostics giving access to real-time information. In the following, we present a selection of outstanding results obtained during recent space missions, carried out on different facilities and devoted to the study of directional solidification with in situ observation.

\subsubsection{Large-scale dynamics of cellular arrays in bulk samples}

Real-time observation of cell and dendrite arrays in bulk transparent-alloy samples has been performed in the DSI instrument, installed on the DECLIC/CNES facility of the ISS (Section 3.2.3). Thanks to a drastic reduction of convection effects, microgravity experiments have allowed to create spatially extended solidification patterns with a relatively uniform spatial distribution, as required for benchmark data and for analysis of the fundamental mechanisms of pattern formation, and spacing selection 62. Unprecedented observations of secondary instabilities of cellular patterns have thus been made possible [57, 176]. In the DSI experiments, cellular patterns with a local hexagonal order presented a marked topological disorder on a large scale, which persisted over the whole solidification time (Fig. 8), and was accompanied by cell-splitting and/or elimination events. In some conditions, an oscillatory mode has been identified within a narrow range of growth parameters (including the intercell spacing) -note that periodic oscillatory patterns had been previously observed and analysed in detail in 2D cellular and dendritic patterns in thin samples (see Sections 4.1 .2 
above, and 5 below), but not in 3D experiments during DS. Cells were observed to oscillate with a well defined time period, within experimental accuracy, but the oscillations were spatiotemporally uncorrelated at long distance. In (scarce) domains displaying a pronounced hexagonal order, the oscillating mode was shown to correspond to an alternate oscillation of the three sub-lattices of the hexagonal arrangement with a phase relation of approximately $\pm 2 \pi / 3$ (Fig. 8). This mode had been previously predicted in numerical simulations of perfectly hexagonal cell structures [177, 178, 179. In the experiments, small squaredordered domains have also been observed, with an alternate oscillation of two sub-patterns. In conclusion, the irregular character of the oscillations appears to be essentially related to the spatial disorder of the cell pattern (also see similar observations in rod-like eutectic patterns; Section 5.3. Incidentally, transient doublons (and "multiplons") have also been observed during DSI experiments (Fig. 3b). These observations illustrate the complexity of the dynamics of cellular patterns in a 3D geometry.

Quantitative measurements of cell-spacing distributions in DSI experiments evidenced a marked influence of finite-size effects on the cell-pattern dynamics and spacing-selection processes. Clear light can be cast on this analysis by noting that, due to the different heat conductivity of the three media in contact - the solid, the liquid and the container walls- the isotherms, thus the solidification front, are generally not planar in bulk samples. They present a finite curvature on a scale comparable to that of the container diameter, even at rest $(V=0)$. This instrumental effect, which is not specific to the DSI instrument, cannot be avoided, except for very special situations. Moreover, it is not smoothed out under microgravity. The curvature of the isotherms varied as a function of $V$ during DS, due to the release of latent-heat and accumulation of solute. 715 Along the curved front, cells are forced to drift toward, or outward the centre of the cylindrical sample, depending on the sign of the curvature (for an inspiring study in 2D, see [180]; also see Section 5.3). This is probably the main source of disorder in cell patterns. It is important to stress that only in situ experimental studies are capable of revealing the qualitative and quantitative effects of non- 


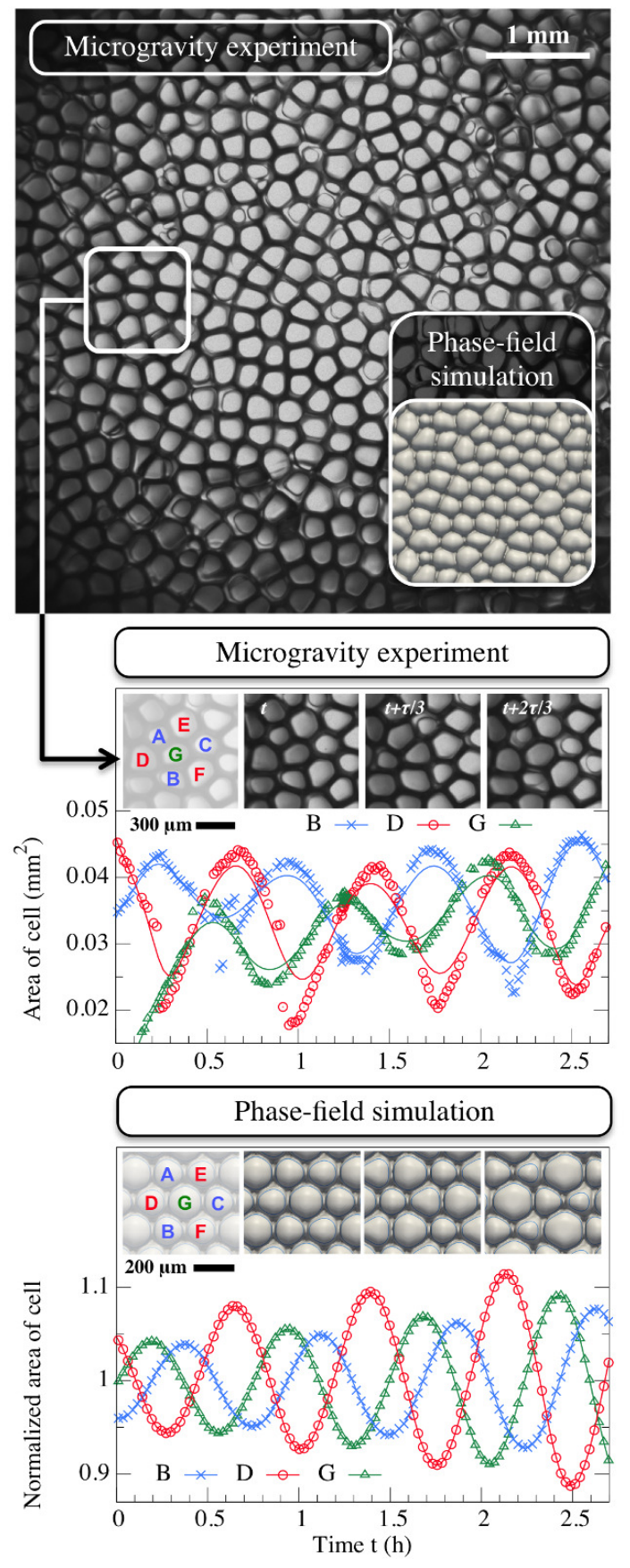

Figure 8: Microgravity experiment: top view observation of an oscillating cellular growth pattern (DECLIC-DSI experiments onboard ISS; SCN-0.24\%wgt Camphor; $V=1 \mu \mathrm{m}^{-1}$; $G=19 \mathrm{Kcm}^{-1}$ ). Note the high disorder of the pattern (also see the phase-field simulation in the inset). Framed area and arrow: short-range correlation of the oscillations; three sub-groups of cells oscillate with a mutual phase difference of $\pm 2 \pi / 3$. This behaviour is clearly identified in groups of cells that present a well-ordered hexagonal packing. It is well reproduced in phasefield simulations (bottom). Courtesy N. Bergeon, D. Tourret. For details, see Ref. [176]. 

with a device similar to DSI under terrestrial conditions gave clear evidence that the deformation of the solidification front was dramatically increased when coupled with fluid flow. In unfavourable cases, at pulling velocities above the (nominal) cellular threshold, the cellular instability remained localised at the radially, and a non-uniform microstructure was eventually established, with a smooth region persisting near the wall. As stated above, this dramatic effect was successfully suppressed under microgravity conditions.

\subsubsection{Dendrite fragmentation}

The formation of columnar microstructures during casting is favourable in practice when directional mechanical properties of the solidified material are required -notably for turbine blades. In contrast, equiaxed microstructures provide more isotropic properties, and are interesting for, e.g., automotive and biomedical components. For an improved control of the solidification process of the columnar to equiaxed transition is therefore crucial. According to a most commonly admitted scenario [182, new dendritic grains form during casting via a process of secondary-arm fragmentation, followed by the transportation of fragments by convection or buoyancy in the liquid far from the leading columnar front (we do not consider inoculated alloys with intensionally added foreign particles serving as easy nucleation sites for the solid). As surmised a long time ago by Jackson and co-workers [183, capillarity pinching and constitutional remelting are dominating mechanisms in a dendrite-arm fragmentation process. However, our knowledge in this domain still remains relatively poor. First

in situ studies on fragmentation were conducted on transparent alloys. Some observations made during normal-gravity experiments and microgravity experiments in sounding rockets by Johnston and Griner suggested that an influence of gravity on fragmentation cannot be completely ruled out 184. Paradies and co-workers could analyse the influence of forced convection on fragmentation 
dynamic shear forces may play a role [185. Interestingly, it was also evidenced that fragment detachment rarely occurs during steady state solidification, but can be promoted by a steep decrease of the growth rate [186]. This effect was attributed to a sudden increase of the concentration of the interdendritic liquid, and an acceleration of the necking of secondary arms.

With the improvements of X-ray synchrotron radiography in terms of spatial and time resolutions, it is now possible to study in situ and real-time the dynamics of fragmentation in metallic alloys, and the subsequent motion of fragments in the liquid. The first quantitative X-ray study of that kind was the work by Yasuda et al, who studied the formation of "stray crystals", and the detachment of dendrite arms during solidification of a Sn-Bi alloy [80. Mathiesen and co-workers also reported observations during upward directional solidification of a Al-Cu alloy 90. It was found that dendrite fragmentation is initiated by gravity induced liquid flow inside the mushy zone. Similar conclusions about the effect of variation of growth rate on dendrite fragmentation were achieved by Jung et al during directional solidification of an Al-7wt\%Si alloy [89].

More recently, in order to study the specific effect of natural convection and buoyancy on dendrite fragmentation, in situ solidification experiments have been performed with the XRMON-GF facility described above in Section 3. The effective spatial X-ray imaging resolution of the XRMON-GF device indeed allows one to accurately follow the motion of dendrite fragments. A comparison was made between solidification experiments (Al-20 wt\% Cu alloy) carried out at $1 \mathrm{~g}$ (vertical sample) and in $\mu \mathrm{g}$, in both cases with in situ characterisation. As expected, experiments carried out on earth showed numerous fragmentation events, most of them occurring in the leading part of the columnar front [187. After detachment, the fragments moved upward due to buoyancy (in Al-Cu alloys, the Al-rich solid is less dense than the $\mathrm{Cu}$-rich liquid), and their size decreased progressively by melting in the hot-liquid region (Fig. 9). For the time being, the X-ray imaging resolution of XRMON-GF (in the $5-10 \mu m$ range) is 780 
microgravity experiments, dendritic fragments were detected, but only deeply into the mushy zone (Fig. 10). In that region, the motion of the fragments was drastically reduced, and difficult to image. Surprisingly, dendrite fragments moved, in average, towards the cold region of the sample, that is, in a direction opposite to that observed in $1 \mathrm{~g}$ experiments. More precisely, the fragments moved along interdendritic channels downward into the mushy zone. This indicates that some fluid flow occurs within interdendritic channels, independently of gravity-induced phenomena, most probably due to the solidification-induced shrinkage (density change upon solidification); see [188 and refs. therein. This inward liquid flow could also be at the origin of fragmentation in the deep region of the mushy zone as discussed in Ref. 90. This shrinkage-induced fluid flow is obviously not gravity dependent, and thus exists even in microgravity conditions, as well as in thin samples. Finally, dendrite fragmentation at the top of the mushy zone did not occur in $\mu \mathrm{g}$, which indicates that buoyancy forces, and remelting mechanisms, were indeed suppressed. This work gives a convincing demonstration of the capabilities of X-ray radiography not only for groundbased research, but also for microgravity experiments. It is also important to stress that, according to those observations, dendrite fragmentation does not occur as a purely diffusive process. It thus differs qualitatively form most of the other solidification pattern formation phenomena presently reviewed, for which both gravity effects (natural convection, buoyancy forces, mechanical forces and hydrostatic pressure) and shrinkage flow can be assumed to have a weak, if not negligible, influence.

\subsection{Faceted growth}

Faceted growth is observed in intermetallic, ceramic-oxide, semi-conductor, quasi-crystal and many organic (e.g., proteins) systems. At equilibrium, a facet corresponds to a deep, singular minimum (or cusp) in the $\gamma$-plot of the solidliquid interface, and generally aligns with a high-density crystallographic plane. Facet growth occurs by step flow along the interface, and depends critically on the density of active step sources, mostly crystal lattice defects (dislocations) 

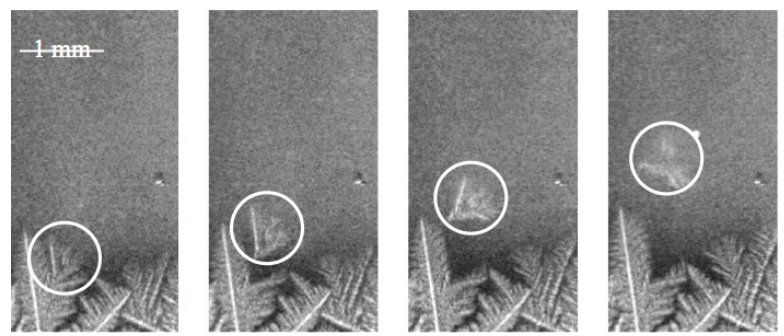

a) $t_{0}$

b) $t_{0}+5 \mathrm{~s}$

c) $t_{0}+11 \mathrm{~s}$

d) $t_{0}+18 \mathrm{~s}$
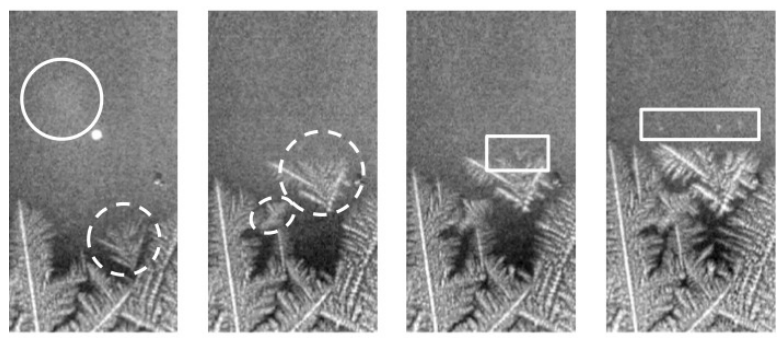

e) $t_{0}+23 \mathrm{~s}$

f) $t_{0}+39 \mathrm{~s}$

g) $t_{0}+45 \mathrm{~s}$

h) $t_{0}+69 \mathrm{~s}$

Figure 9: Sequence of X-ray radiographs showing dendrite-fragmentation events, and the upward motion of dendrite fragments during solidification (vertical sample) under normal (1g) gravity conditions in the XRMON-GF apparatus (Al-20wt\% $\mathrm{Cu} ; \mathrm{G}=15 \mathrm{Km}^{-1}$; cooling rate $\left.R=-0.15 K s^{-1}\right)$. For details see Ref 187 . 

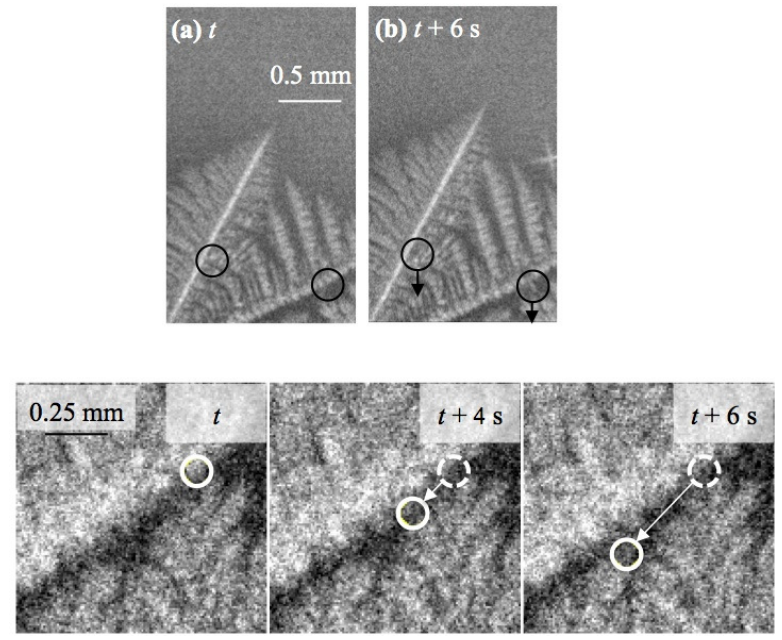

Figure 10: Top: X-ray radiographs showing the position and the subsequent motion of dendrite fragments (black circles) inside the mushy zone during a $\mu \mathrm{g}$ solidification experiment in the XRMON-GF apparatus (Al-20wt\% $\left.\mathrm{Cu} ; G=15 \mathrm{Kmm}^{-1} ; R=-0.15 \mathrm{Ks}^{-1}\right)$. The time interval between (a) and (b) is $6 \mathrm{~s}$. Bottom: Downward trajectory of a dendrite fragment along an interdendritic liquid channel. Also see Ref. 187.

intersecting the interface [189, 190]. This slow, nonlinear kinetics often leads to very unsteady growth regimes. In some "weakly" faceted systems, however, macroscopic facets present a high mobility even at small undercooling, and grow in a way similar to that of the atomically rough regions of the solidliquid interface. Steady faceted dendrites have been observed in free growth of pivalic acid [191, and their morphological-selection laws found not to differ qualitatively from that of nonfaceted dendrites [192, 193. Periodic arrays of faceted cells and dendrites have also been observed in thin samples of impure biphenyl, leading to the same conclusion [194. Complex faceted patterns such as those observed during bulk solidification of Bi-Sb alloys [195] have not been reproduced so far in transparent alloys, and still remain to be understood.

Silicon, as other semiconductors, is also representative of weakly faceted systems. It is an "intermediate" compound in the sense of Jackson's classification, in that its growth is mostly rough except for one family, namely, $\{111\}$ planes, of facet orientations. It is worth noting that, due to the shortage of electronic-grade 
silicon, photovoltaic industry has started moving to multicrystalline metallurgical silicon. However, grain boundaries, including twin boundaries, are globally detrimental to electronic properties of the final product. In situ observation during silicon crystal growth is a clear challenge due to the high solidification temperature (about $1500^{\circ} \mathrm{C}$ ). Real-time observations using an optical microscope [196] and X-ray radiography (and topography) 197] were successfully carried out recently. A characterisation of the dynamics of grain growth and competition, in relationship with twinning phenomena, has been achieved. An important observation is that of the nucleation of twinned grains at the bottom of the deep faceted grooves that decorate grain boundaries intersecting the solidliquid interface [198. The depth of a faceted GB groove, as well as its drifting motion, are mainly determined by the slow, possibly blocked growth kinetics of the facet. The extension of the facet down to low temperatures is limited by step sources that become efficiently active at the bottom of the groove. Interestingly, there may exist a phenomenological similarity between those faceted GB-grooves during silicon solidification (Fig. 11) and a localised pattern called "faceton" observed during thin-DS of a lamellar crystal [35.

Another important compound also solidifies in a faceted way: water. Plateletlike ice crystals grow with facets parallel to the basal plane of the hexagonal 845 lattice, and a (sharp) edge (missing orientations). Among the numerous experimental studies on that subject, let us mention a careful investigation by Furukawa and coworkers, using real-time observation of single crystals in microgravity conditions (pure heavy water was used for instrumental reasons) [199]. As expected for a hexagonal anisotropy, (thermal) dendrite fingers were observed to grow along six directions (also see 200]). Interestingly, two distinct dynamical behaviors were identified depending on whether the basal facets grow (larger undercoolings) or remain macroscopically blocked (lower undercoolings). The measured interfacial-kinetics crossover most probably coincides with a change in the growth mode of the facets (for a theoretical analysis of the destabilization 855 of platetel crystals, see also [201]). 

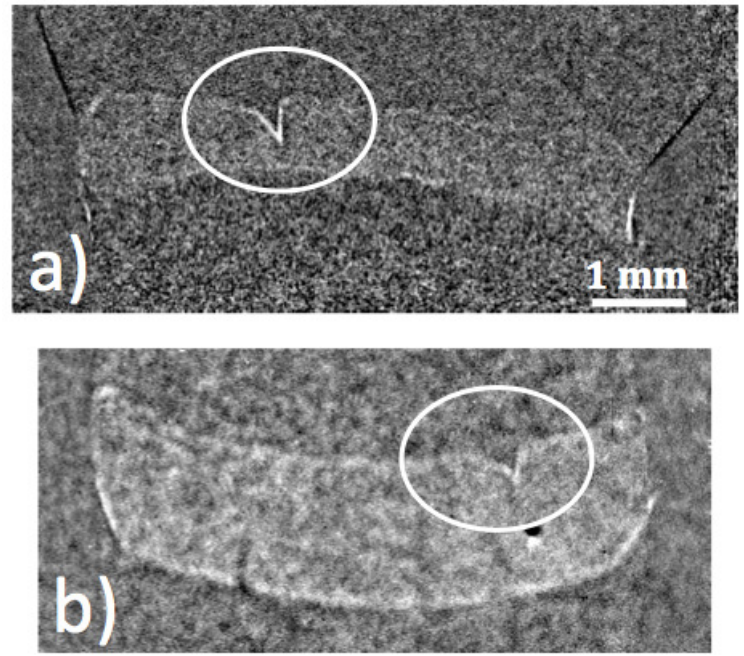

Figure 11: Two successive images during directional solidification of pure polycrystalline silicon by X-ray radiography (see Ref. [198). See the lateral drift of a faceted grain-boundary cusp. The same cooling rate $R=0.5 \pm 0.02 \mathrm{Kmin}^{-1}$ was applied on both heaters (fixed sample). a) $V=8 \pm 0.03 \mu \mathrm{ms}^{-1} ; G=10 \pm 0.4 \mathrm{Kcm}^{-1}$. b) $V=23 \pm 0.03 \mu \mathrm{ms}^{-1} ; G=$ $15 \pm 0.4 \mathrm{Kcm}^{-1}$. In the two images, the bright band in the solid is a result of the image processing method (image-division) employed to enhance the contrast, and has no physical meaning. Courtesy: N. Mangelinck-Noël. 


\section{Eutectic solidification in nonfaceted systems}

\subsection{Thin eutectics}

\subsubsection{Binary eutectics}

A binary eutectic alloy possesses an interval of concentrations (eutectic plateau) within which two solid phases (of concentrations corresponding to the edges of the eutectic plateau) can coexist at equilibrium with the liquid (concentration $C_{E}$ ) at the eutectic temperature $T_{E}$. Directional solidification of such an alloy generally delivers a two-phase solid. Eutectic microstructures are present in interdendritic grooves (microsegregation) for substantially off-eutectic concentrations. They are observed as bulk as-grown composites (coupled-growth) for concentrations closer to $C_{E}$. Metallic eutectics are interesting, in particular, as solder alloys, and ceramic-oxide eutectics as potential self-organized metamaterials [15, 202. Here, we are interested in coupled-growth processes, during which the two solids grow simultaneously.

Binary-eutectic microstructures are made, in a first approach, of regular arrays of lamellae or fibers (rods) of the two eutectic-solid phases (generically noted $\alpha$ and $\beta$ ). They result from two-phase solidification front patterns with banded or hexagonal periodicity, respectively [203]. Roughly speaking, rod-like eutectics mainly form when the volume fractions of the two solid phases are very different, whereas lamellar eutectics are more commonly observed for more or less equal volume fractions. Following the first theoretical insight by Zener in 1946 [1] (also see 204]), a coherent theory of regular eutectics in directional solidification was proposed by Jackson and Hunt (JH) [12. Under realistic approximations (planar front; $\lambda V / D<<1$ ), it was demonstrated that, at given $V, G$ and liquid concentration $C_{0}$, periodic eutectic patterns can exist over a continuum of values of the (interphase) spacing $\lambda$, and are essentially insensitive to $G$. Moreover, there exists a scaling parameter, the so-called minimum undercooling spacing $\lambda_{m}$, which varies with $V$ as $V^{-1 / 2}$, and corresponds to the value of the spacing at which diffusion in the liquid and capillarity equally contribute 
of eutectic patterns depends on a single parameter, say $\lambda / \lambda_{m}$, which is proportional to $\lambda V^{1 / 2}$ [205]. In steady-state, the system most commonly operates close to $\lambda_{m}$, but, at given $V$, different kinds of morphologies are accessible, and $\lambda$ can vary within a wide interval.

Thin-DS of transparent eutectic alloys has been developed by Jackson and Hunt [12, and reintroduced by Trivedi and collaborators [206, and Faivre and collaborators 207] in the 1980's, in order to test the 2D morphological stability of periodic patterns. It has been more extensively and quantitatively used since then [42, 208, 209, 210], and the method has been extended to thin metallic films [53, 211. Thin-DS presents the advantage that the dynamic response (in 2D) of a steady-state lamellar pattern (also called "basic state"; Fig. 12 p) to changes of $V$ can be observed by keeping unchanged the number of lamellae (thus the average spacing) in large eutectic grains (see Section 5.2. This allows one to scan a large parameter range in terms of $\lambda / \lambda_{m}$. In brief, for a large range of alloy concentrations in the eutectic plateau, basic-state patterns can exist within a finite interval of spacing (about $0.7-2.2 \lambda_{m}$ at eutectic concentration). At large spacings, various morphological instabilities are observed, which fully preserve the coupled-growth dynamics, but bring the system into new periodic patterns with a broken symmetry. The limiting instability mode, and the limit spacing depend on the concentration of the alloy. Such symmetry-broken patterns can be travelling (Fig. 12p), oscillatory (Fig. 12 ), or possess both travelling and oscillatory features.

The long-term stability of a basic-state lamellar pattern can be tested by following the evolution of a slight modulation of the spacing profile $\lambda(x, t)$. Inside the stability interval, the growth front pattern undergoes a slow uniformisation process, which generically obeys a spacing diffusion equation (usually called "phase diffusion" in the nonlinear-physics literature [30]). Based on a pioneering work by Langer [212, 213], and with the help of numerical simulations, a semi-empirical expression of the spacing diffusion coefficient $D_{\lambda}$ was obtained 915 as a function of alloy parameters (including $\lambda_{m}$ ) and, crucially, of $\lambda, V$ and $G$ [214, 215]. Knowing this, in situ measurements of $D_{\lambda}$ can be used to estimate 


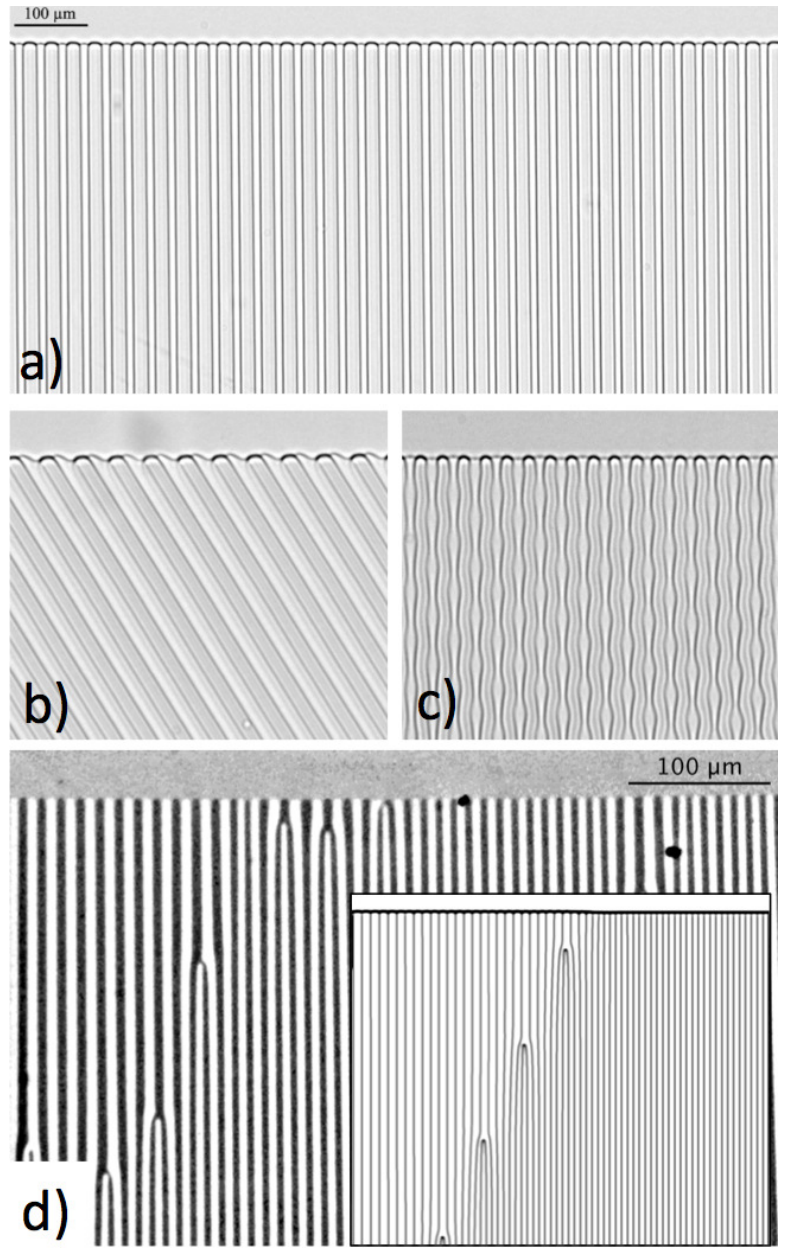

Figure 12: Eutectic growth patterns in thin-sample directional solidification. a) Steady periodic pattern (slightly hypereutectic $\mathrm{CBr}_{4}-\mathrm{C}_{2} \mathrm{Cl}_{6}$ transparent alloy; $V=1 \mu \mathrm{ms}^{-1}$; $\lambda \approx 1.2 \lambda_{m}$ ). The solidification axis is vertical (liquid on top). Liquid and solid-solid interfaces are seen as dark lines. b) Travelling pattern (same alloy; $V=2 \mu m s^{-1} ; \lambda \approx 2.15 \lambda_{m}$ ). c) Oscillatory pattern with period doubling (same alloy; $V=2 \mu m s^{-1} ; \lambda \approx 1.35 \lambda_{m}$ ). d) Lamella eliminations after a downward velocity jump from 0.7 to $0.35 \mu \mathrm{ms}^{-1}$ (near-eutectic In- $\mathrm{In}_{2} \mathrm{Bi}$ alloy; the $\mathrm{In}_{2} \mathrm{Bi}$ phase appears black, the In-rich phase white). Inset: phase-field simulation showing a propagative process involving periodic lamella elimination events (M. Plapp). See Ref. 215. 
the value of thermophysical quantities of the alloy [42, 211, 216]. In addition, it was shown that the sign of $D_{\lambda}$ changes at a spacing value that corresponds to the lower stability limit $\lambda_{c}$ of 2D eutectic patterns (Eckhaus instability). For $\lambda<\lambda_{c}$, the system is unstable upon a lamella elimination instability (Fig. 12 d) that brings it back into the stability interval. The ratio $\lambda_{c} / \lambda_{m}$ is sensitively smaller than 1 for ordinary DS conditions (hence the proposed term of "overstability"), and depends on $G / V$ (it tends to 1 when $G / V$ increases) [214, 215]. Both experiments and numerical simulations show that, starting with an initially uniform pattern, lamella eliminations can occur in a propagative way (Fig. 12 d).

A complete 2D morphology diagram (stability limits as a function of alloy concentration) has been obtained experimentally [209, in good agreement with numerical simulations [217, for the $\mathrm{CBr}_{4}-\mathrm{C}_{2} \mathrm{Cl}_{6}$ transparent alloy (also see Refs. [42, 211]). Other remarkable spatio-temporal phenomena were also discovered 156, 208.

\subsubsection{Ternary eutectics}

Laboratory research in the domain of ternary eutectic solidification has been initiated very recently. Depending on physical parameters and growth conditions, the solidification of a ternary eutectic alloy delivers multiscale microstructures that are composed of one-, two- and three-phase regions in coexistence in the solid [218]. Eutectic cells and colonies, which we will consider first, are observed during univariant solidification along a eutectic valley in the ternary phase diagram. This typically occurs when a third compound is added to a binary eutectic alloy of reference, and that compound is rejected like an impurity by the two-phase solid, and diffuses in the liquid. In directional solidification, a fingering instability of the composite growth front occurs above the threshold velocity $V_{c}$ of an effective Mullins-Sekerka instability, on a scale much larger than the eutectic spacing [219]. The eutectic-cell instability is made complex, as compared to ordinary cells, by a nonlinear interaction between the cellulation

${ }_{945}$ and the eutectic growth [220, 221]. In practice, eutectic-cell patterns arise via the mediation of local structures, such as the two-phase finger 222. In ternary 
alloys containing a small amount of the third component, the average size of the eutectic cells decreases when $V$ increases, but no clear scaling behaviour was observed. Moreover, eutectic-cell patterns exhibit an unsteady dynamics (also see [60] for bulk transparent alloys, and 223] for metallic alloys). In some alloys, the shape and the stability of eutectic cells can also depend markedly on the crystal orientation of the eutectic grain 224,225$]$.

During univariant eutectic growth with a large amount of the third component, highly branched structures and eutectic dendrites are observed [219, 226]. A novel ternary-eutectic growth shape called spiral(ing) two-phase (or eutectic) dendrite (in short, spiral dendrite) has been discovered and characterised by real-time observations in a nonfaceted transparent alloy [227. Like a one-phase dendrite, a spiral dendrite is a nearly paraboloidal finger-like shape with sidebranches (Fig. 13 ). Eutectic growth starts from a spiral pattern located at the tip. This geometry permits continuous growth of the two eutectic solids along the curved solid-liquid interface. This intrinsically 3D growth mode delivers an intricate $\alpha \beta$ helicoidal microstructure in the solid. The tip radius of curvature $\rho$ and the eutectic spacing $\lambda$ were measured as a function of $V$. Both $\rho$ and $\lambda$ were found to be very close to each other, and to the minimum undercooling spacing of the binary eutectic alloy of reference. In other words, spiral dendrites obey a clear morphological selection process, with $\rho \sim \lambda \sim V^{-1 / 2}$, independently of interfacial anisotropy [228]. Note that the spiral dendrite is favoured by an equal volume fraction of the two solids and an overall composition close to a eutectic valley of the alloy. In contrast, the above mentioned two-phase finger (made of two large asymmetric fingers of one solid phase sandwiching a thin crystal of the other solid) is more characteristic of off-eutectic compositions. Both the two-phase finger 222 and the spiral-dendrite (Fig. 13b) 2229, 230] have been reproduced in phase-field simulations. Clear experimental evidence of spiral dendrites in metallic alloys is still lacking.

975 Nonvariant solidification of ternary-eutectic alloys of composition close to a eutectic point at the intersection of three eutectic valleys occurs via a coupledgrowth dynamics of three solid phases, here conveniently noted $\alpha, \beta$ and $\gamma$. 


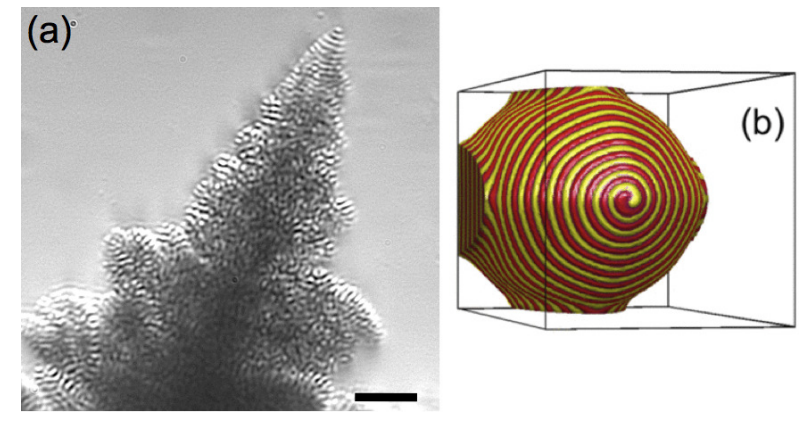

Figure 13: Spiral two-phase dendrites. a) Real-time observation (side view) during directional solidification of a transparent ternary alloy (also see Ref. 227. for details). Bar: $20 \mu \mathrm{m}$. b) Phase-field simulation (reprinted with permission from Ref. 229], Copyright 2012, AIP Publishing LLC).

This problem is very complex, due, in particular, to the large variety of tiling motifs that three-phase solidification front patterns can possibly adopt. In a $2 \mathrm{D}$ geometry, one can note $\alpha \beta \gamma, \alpha \beta \alpha \gamma, \alpha \beta \alpha \beta \alpha \gamma$, etc, the periodic-stacking motif. Theoretically (JH-type analysis), one can derive a motif-dependent minimumundercooling spacing $\lambda_{m}$ [231, 232, and show that $\lambda_{m}\left(\sim V^{-1 / 2}\right)$ is a relevant scaling quantity. A thin-DS study of two ternary eutectic alloys of totally dif-

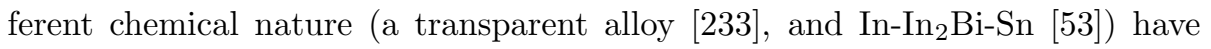
confirmed this scaling behaviour for lamellar patterns with an $\alpha \beta \alpha \gamma$ stacking motif (Fig. 14). A morphological-stability study of the $\alpha \beta \alpha \gamma$ patterns is in progress 234 (symmetry-breaking instabilities, lamella elimination, stability against, e.g., $\alpha \beta \gamma$ patterns [232]). In bulk samples, three-phase growth microstructures most commonly exhibit a marked spatial disorder, and a strong eutectic-grain dependence (see, e.g., Refs [44, 235, 236, 237]).

\subsection{Eutectic grains}

In the previous two sections, the systems were considered as being fully isotropic. Crystallographic effects were ignored. In many binary-eutectic alloys, however, solidification microstructures are known to differ between different eutectic grains [238, 239]. Thin-sample DS has been recently used for demonstrating the effect of a strong anisotropy of the interphase boundaries in the eutectic 


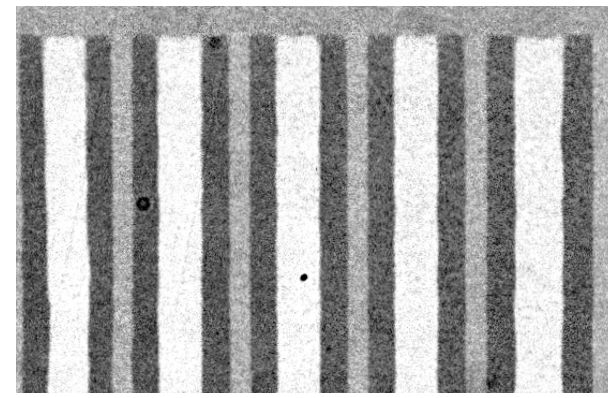

Figure 14: Three-phase $\alpha \beta \alpha \gamma$ growth pattern. Thin-sample directional solidification $(V=$ $0.13 \mu \mathrm{ms}^{-1}$ ) of a In-In ${ }_{2}$ Bi-Sn ternary eutectic alloy (S. Bottin-Rousseau). The In-rich $(\beta)$ solid solution appears white, and the $\operatorname{In}_{2} \operatorname{Bi}(\alpha)$ intermetallic black. The Sn-rich phase $(\gamma)$ is of nearly the same grey as the liquid. Horizontal dimension: 250 $\mu \mathrm{m}$. Also see Ref. 53.

solid on the growth dynamics of eutectic alloys. This should provide a basic support for a better understanding of the selection of eutectic grains with a special orientation relationships (OR) between the $\alpha$ and $\beta$ crystals in bulk samples. In a eutectic grain, the two solid phases have a fixed crystal-lattice orientation. The free energy of an $\alpha-\beta$ interphase boundary, as well as its anisotropy, are fixed within a given grain, and vary between different grains [238, 240. In nonfaceted binary eutectic alloys that present at least one (hetero-)epitaxial OR, the eutectic growth dynamics is dramatically modified. In lamellar eutectics, one observes a dynamic "locking" of the interphase boundary onto a coincidence plane (Fig. 15a) that corresponds to a deep minimum of the free energy of the interphase boundary as a function of its inclination. This entails, in particular, the growth of microstructures with tilted lamellae (Fig. 15. also see Fig. 3b in [210]). In contrast, in isotropic eutectic grains, the lamellae (in the basic state) follow the direction of the thermal gradient ("floating" grains ; see Fig. 12a).

The anisotropy of the interphase boundary enters the theory of eutectic growth in the local equilibrium (Young-Herring) condition at the $\alpha$ - $\beta$-liquid trijunctions. Key experimental observations indicate that the shape of the solidliquid interfaces remains approximately symmetric with respect to the mid-plane between two neighbouring trijunctions, in spite of the lateral drift of the pattern 

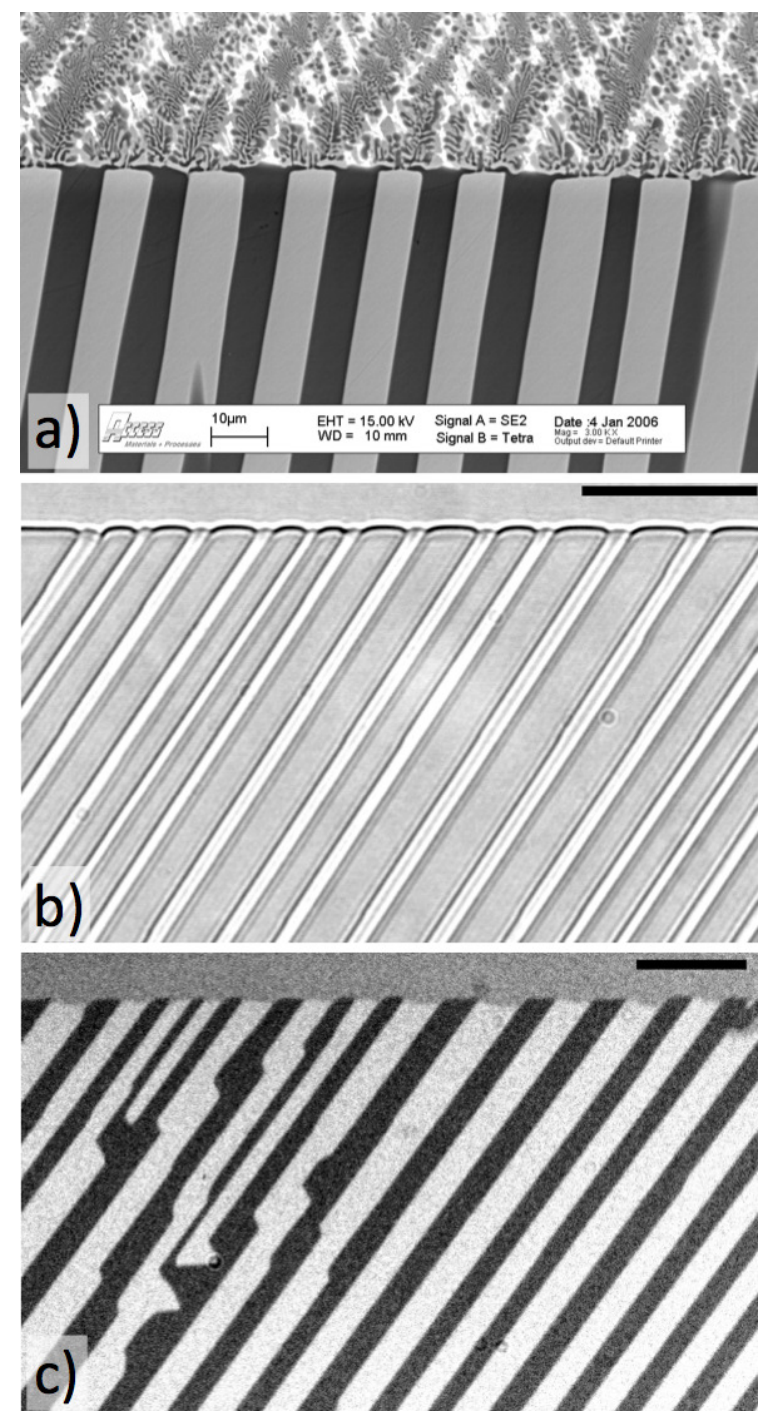

Figure 15: Locked eutectic grains in directional solidification of nonfaceted eutectic alloys. a) Longitudinal section (SEM micrograph) of a quenched bulk sample of an $\mathrm{Al}-17.5 \mathrm{~mol} \% \mathrm{Cu}$ $1.0 \mathrm{~mol} \% \mathrm{Ag}$ alloy $\left(V=2.43 \mu \mathrm{ms}^{-1}\right)$. Courtesy U. Hecht (also see Ref. 225]). Thin samples (bars: $50 \mu m)$ : b) $\mathrm{CBr}_{4}-\mathrm{C}_{2} \mathrm{Cl}_{6}\left(V=0.5 \mu m s^{-1}\right)$; c) $\operatorname{In}_{-} \mathrm{In}_{2} \mathrm{Bi}\left(V=0.15 \mu m s^{-1}\right)$. Also see Refs. 241, 242. 
(this is visible in Fig. 15p). This yields a symmetric-pattern condition (namely, the surface tension vector of the interphase boundary is parallel to the thermalgradient axis) that fixes the contact angles at the trijunction [241. Thus, the tilted-growth direction can be determined if the anisotropy of the interphase

boundary is known. That conjecture was tested by $2 \mathrm{D}$ numerical simulations 243. A good agreement between simulated and predicted tilt angles was found, and the dynamic lamellar-locking effect confirmed.

This result -the relevance of the symmetric pattern approximation- also leads to an interesting conclusion, which concerns the practical use of an experimental method in which the (thin) sample, instead of being translated along the $\mathbf{z}$ axis, is continually rotated with respect to the temperature gradient (rotating directional solidification) [242. If the centre of rotation is aligned with the solid-liquid interface, the alloy melts on one side, and solidifies on the other side with the local growth velocity varying linearly along the growth front axis ( $V$ ramp). During this process, a given eutectic grain is rotated continuously while growing. For a floating, isotropic eutectic grain, the lamellae grow locally perpendicular to the planar isotherm, and the microstructure left in the solid is made of circular lamellae. This observation justifies the assumption of a quasistatic dynamics over a large region where the effect of the lateral $V$ ramp can be neglected. In anisotropic eutectic grains, rotating-solidification microstructures possess a 2-fold symmetry, which is expected for a crystal-crystal interface. More precisely, it was shown that quantitative information on the anisotropy function of the interphase boundary energy can be extracted from the analysis of the shape of the lamellae in a rotating-solidification microstructure [241, 242].

Again, the combination of in situ experiments and numerical simulations revealed a great efficiency. However, many questions still remain open in this context. In 2D, the large-scale dynamics of locked-lamellar eutectics is not understood (inefficiency of the spacing-diffusion process, kink-like features in the microstructure; see Fig. 15.). In 3D, the effect of the anisotropy of interphase boundaries on pattern selection in bulk samples (lamella-to-rod transition) has not yet been addressed. Finally, there still remains a need of experiments in 
systems where direct information on the properties of the interphase boundary can be obtained (e.g., by atomistic simulations; see Ref. [244]), and in which the orientation of the crystals are known.

\subsection{Bulk eutectics}

Both lamellar and rod-like eutectic patterns (Figs. 1 $\mathrm{b}$ and 11) have been observed during bulk-DS by using the DIRSOL apparatus (see Section 3.2.3). Isotropic systems were examined, and near-eutectic alloys used, in order to avoid thermo-solutal convection. In lamellar eutectics $\left(\mathrm{CBr}_{4}-\mathrm{C}_{2} \mathrm{Cl}_{6}\right)$, a zigzag instability has been identified [245] (Fig. 16a), which corresponds to a transition from straight lamellae to wavy or "chevron" patterns (for a phenomenological study of the zigzag bifurcation, see Ref. 30). This instability occurs for a spacing value slightly below $\lambda_{m}$, according to experiments. Phase-field simulations in 3D [246, 247] have indeed established that all the other instability modes observed in thin samples (see Section 5.1.1), which would virtually grow at high spacing values, are hidden by the zigzag mode over the whole domain of investigation. The zigzag-instability threshold therefore represents the upper stability limit of bulk lamellar eutectic patterns. In contrast, the dynamics in the vicinity of the lamella elimination threshold (lower stability limit) has not been studied yet, to our best knowledge. The lamella branching mechanism, which has been evidenced in a bulk-DS study of eutectic $\mathrm{Al}-\mathrm{Al}_{2} \mathrm{Cu}$ alloys [248, still remains to be studied by real-time observations. The problem of the fault lines that are present in large density in cross-sections of bulk lamellar-eutectic materials also remains largely open [225, 245].

In bulk-DS of lamellar-eutectic alloys, it was observed that the eutectic front did not self-organize into a well-ordered lamellar pattern, but remained disordered during the entire solidification time (Fig. 16p). Such "labyrinth" patterns were also systematically observed in simulations using a random arrangement as an initial guess. No ordered lamellar state was reached even in the longest experiments or simulations 249. This signals the absence of a strong interfacialanisotropy effect in the system -generally speaking, ordering of stripe patterns 


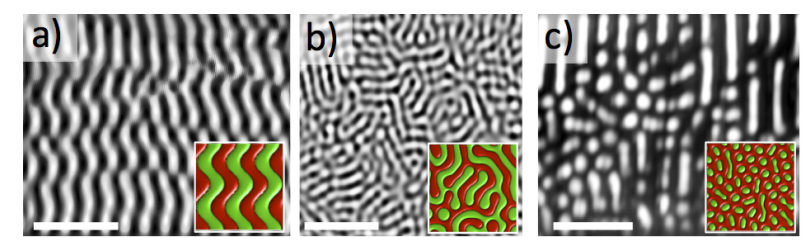

Figure 16: Eutectic growth patterns in bulk directional solidification. Real-time (top-view mode) observations (DIRSOL setup) in transparent alloys: a) Zigzag pattern $\left(\mathrm{CBr}_{4}-\mathrm{C}_{2} \mathrm{Cl}_{6}\right.$; $\left.V=0.39 \mu \mathrm{ms}^{-1}\right)$; note the presence of "phase jumps", reminiscent of the fault lines in metallic ingots (see Ref. 245]). b) Labyrinth pattern $\left(\mathrm{CBr}_{4}-\mathrm{C}_{2} \mathrm{Cl}_{6} ; V=1.0 \mu m s^{-1}\right.$; see Ref. [250]). c) Coexistence between rods, elongated rods and broken lamellae (SCN-DC; $V=0.01 \mu \mathrm{ms}^{-1}$, see Ref. 251]). Bars: $100 \mu \mathrm{m}$. Insets: 3D phase-field calculations (eutectic alloy with symmetric phase diagram) 247 249].

in large isotropic systems is extremely slow [5]. Then, the question arises of knowing how do regular (straight or zigzag) lamellar eutectics form within an ordinary experimental time. The answer is that this occurs easily when the isotherms are not exactly perpendicular to the main growth axis, but slightly slanted, due to a (possibly tuneable) asymmetry of the instrument 250]. The thermal misalignment imposes a global drift of the pattern, thus a progressive elimination of the initial labyrinth pattern, and the propagation of a well-ordered lamellar pattern.

Rod-like eutectics (Fig. 17) are generally observed to organise into hexagonalorder domains. In situ experiments (SCN-DC) indicate that, at given $V$, the stability interval of the rod spacing is limited by elimination (lower limit) and splitting (upper limit) of individual rods [252, 253. The splitting instability limit is close to (and scales with) $\lambda_{m}$, while the elimination instability occurs for spacing values well below $\lambda_{m}$ (see Section 5.1.1). More complex features are also worth mentioning. First, in the real-time experiments, elongated rods have been observed during transient stages, as a precursor of rod splitting [253], and in confined geometries [251, 254] (Fig. 16; ; also see disordered patterns in metallic alloys $248,255,256$ ). Steady periodic patterns made of dumbbellshaped rods observed in phase-field simulations [249] have not been observed experimentally. Second, oscillatory rod patterns have been observed in real-time 
experiments, and phase-field simulations as well 253. This oscillation dynamics occurred in highly disordered patterns -in this respect, it is similar to the ones observed in cellular patterns in dilute alloys (see Section 4.2.2). However, no regular oscillation mode could be identified in rod eutectics, even locally. Finally, a slight imperfection of the thermal field, namely, a macroscopic (convex) curvature of the isotherms, was observed to impose a continuous stretching of the pattern (the rods grow approximately perpendicular to the front envelope), and thus an increase of the average spacing (also see Section 4.2.2). The system eventually reached a limit operating point when the stretching was balanced by rod-splitting events. At long times, the statistical spacing distribution was measured to be independent of initial conditions. In other words, due to a forcing effect, the system is driven toward an operating point close to a stability limit (the rod splitting threshold). This observation possibly provides an answer to the question of the "selection" of the eutectic spacing [252]. It also opens the question of a partial control of the eutectic spacing by applying a variable pulling velocity program [257].

The question of the lamella-rod transition still remains largely open. There are experimental (coexisting patterns) [256, 258 and numerical (hysteresis) 249] indications that this transition occurs progressively when the alloy concentration is changed (also see Fig. 16c). For a systematic experimental study, samples with alloy concentrations departing significantly form the eutectic point (or with large-scale concentration gradients maintained over long times) should be solidified in a microgravity environment in the absence of natural convection $1120 \quad 59$.

\section{Conclusion and prospects}

In conclusion, in situ solidification with real-time diagnostics performed in well-controlled conditions offers a unique means for in-depth studies of the complex dynamics of growth patterns in the limit of diffusion transport. We stress the following points: (i) by combining both metallurgical and nonlinear-physics 
approaches, in situ experimentation using model or (near-)industrial alloys is strikingly fruitful, and, as a long awaited feedback, timely meets the needs of applied research in solidification processing and casting for well-calibrated experiments and integrated models serving at cast-houses; (ii) microgravity experimentation is an essential part of wide-scope solidification research programs, by both promoting outstanding "on-ground" laboratory work and permitting experimental investigations that would not be feasible in a normal-gravity environment; (iii) the success and the breakthrough character of in situ solidification monitoring promotes the development of new methods (e.g., rotating directional solidification, local control by laser-light micromanipulation) and the use of advanced imaging facilities (bulk-DS imaging, X-ray radiography for metals) ; (iv) the thus obtained quantitative results are unparalleled references for meso-scale theoretical modelling and numerical simulations, and for the implementation of multi-scale predictive models; (v) in situ solidification extends to metrology applications and quantitative investigation of industrial problems.

Several fields of importance were omitted or left aside in this review. In the first place, there are emerging laboratory experiments (following, in particular, a pioneering work by Liu and Hellawell 259]) aiming at studying the effects of strong convection motions in the liquid in well-controlled, model conditions, with full real-time imaging [94, 260]. As initially announced in this text, we did not review fast-solidification phenomena (levitated undercooled droplets [261, laser processes [262, 263]). We also did not consider the rapid development of high-resolution X-ray tomography, in particular for in situ rheology of an alloy maintained in solid-liquid coexistence [264, 265] -there is also emerging work for real-time 3D imaging of dendritic growth in thin capillaries [266]. Some direct observations of monotectic solidification [267, 268] and gas-pore growth in transparent systems [51, 269, 270] are of great interest. There still remains a gaping lack of real-time observations in the domain of peritectic growth (see 271] and refs. therein). Growth phenomena in colloidal suspensions [272, colloidal crystals 273, 274, polymers 275, 276, and amphiphilic monolayers 277] also offer a large variety of pattern formation dynamics. On another note, there are also 
interesting prospective work attempting to use self-organized microstructures (e.g., rod-like eutectics) as new templates for innovative applications in optics [202, 278, 279] (also see [15]).

Many of the studies reported above have raised new questions and opened still unexplored directions for future work in the domain of in situ solidification. Obviously, X-ray imaging methods in $2 \mathrm{D}$ and $3 \mathrm{D}$, and microgravity experimentation will play a major role in near-future work. Closer experimental coupling between real-time observations and crystallographic analysis, and also between atomic-scale and meso-scale calculations, should provide a better understanding of crystal-anisotropy effects. We have stressed above the remarkable synergy between in situ solidification and numerical simulations. The two activities share many challenging features: significant progress is still expected in the field of faceted growth [280] (in particular, the question of morphological transitions in faceted-nonfaceted eutectics, such as Al-Si, has been hardly addressed 216, 281? ]); the space-time dynamics of large systems (formation of domains, topological and travelling defects, grain competition) in well-controlled conditions requires increasingly sophisticated investigation methods. Finally, it is always useful to highlight the inspiring link that exists between fundamental research in laboratories and industry-oriented $\mathrm{R} \& \mathrm{D}$ activities, in particular via the development of thermophysical databases and multi-scale numerical models for casting; constant effort should be made and encouraged to reinforce connecting initiatives in this direction.

\section{Acknowledgments}

We gratefully acknowledge fruitful discussions with B. Billia, G. Faivre, J.F. Garandet, and B. Zappoli. We thank N. Bergeon, S. Bottin-Rousseau, J.-M. Debierre, U. Hecht, A. Karma, W. Losert, N. Mangelinck-Noël, M. Plapp, A. Pocheau and D. Tourret for their contributions to the figures. We thank the French Centre for Spatial Research (CNES) for constant financial support.

\section{References}


[1] C. Zener, Kinetics of the Decomposition of an Austenite, Trans. AIME 167 (1946) 550-595.

[2] B. Chalmers, Principles of Solidification, R.E. Krieger Pub. Co (1977).

[3] W.W. Mullins, RF. Sekerka, Stability of planar interface during solidification of dilute binary alloy, J. Appl. Phys. 35 (1964) 444-451.

[4] J. Langer, Instabilities and pattern-formation in crystal-growth, Rev. of Mod. Phys. 52 (1980) 1-28.

[5] M. Cross, P. Hohenberg, Pattern formation outside of equilibrium, Rev. of Mod. Phys. 65 (1993) 851-1112.

[6] Solids Far from Equilibrium, C. Godrèche ed., Cambridge University Press (1992).

[7] A. Karma, Ch. XI, 365, in Branching in nature, eds Fleury V, Gouyet JF, Leonetti M (Les Houches, vol.13, EDP Sciences, Springer, 2001).

[8] M. Asta, C. Beckermann, A. Karma, W. Kurz, R. Napolitano, M. Plapp, G. Purdy, M. Rappaz, R. Trivedi, Solidification microstructures and solidstate parallels: Recent developments, future directions, Acta Mater. 57 (2009) 941-971.

[9] J.A. Dantzig, M. Rappaz, Solidification, EPFL Press (2009).

[10] N. Provatas, K. Elder, Phase-Field Methods in Materials Science and Engineering, Wiley (2010).

[11] K.A. Jackson, J.D. Hunt, Transparent alloys that freeze like metals, Acta Met. 13 (1965) 1212-1215.

[12] K.A. Jackson, J.D.Hunt, Binary eutectic solidification, Trans. Metall. Soc. AIME 236 (1966) 843-852. K.A. Jackson, J.D.Hunt, Lamellar and rod eutectic growth, Trans. Metall. Soc. AIME 236 (1966) 1129-1142. 
[13] S. C. Huang, M.E. Glicksmann, Fundamentals of dendritic solidification.1. Steady-state tip growth, Acta Metall. 29 (1981) 701-715. S. C. Huang, M.E. Glicksmann, Fundamentals of dendritic solidification. 2. Development of sidebranch structure, Acta Metall. 29 (1981) 717-734.

[14] W.D. Huang, L.L. Wang, Solidification researches using transparent model materials, A review, Sci China Tech Sci 55 (2012) 377-386.

[15] J. Llorca, V. M. Orera, Directionally solidified eutectic ceramic oxides, Progr. Mater. Sci. 51 (2006) 711-809.

[16] E. Rolley, S. Balibar, F. Graner, Growth shape of He-3 needle crystals, Phys. Rev. E 49 (1994) 1500-1506.

[17] U. Bisang, J. H. Bilgram, Shape of the tip and the formation of sidebranches of xenon dendrites, Phys. Rev. Lett. 21 (1995) 3898-3901. U. Bisang, J. H. Bilgram, Shape of the tip and the formation of sidebranches of xenon dendrites, Phys. Rev. E 54 (1996) 5309-5326.

[18] K. Kassner, Pattern Formation in Diffusion-Limited Crystal Growth, World Scientific (1996), ISBN 9810215320.

[19] M.H. Wu, A. Ludwig, A three-phase model for mixed columnar-equiaxed solidification, Metall. Mater. Trans. A 37A (2006) 1613-1631. M.H. Wu, A. Ludwig, Using a Five-Phase Volume Averaging Approach to Model the Mixed Columnar-Equiaxed Solidification, in Modeling of casting, welding, and advanced solidification processes - XII, ed. Minerals, Metals \& Materials Soc (2009) 537-544.

[20] D. Tourret, A. Karma, Multiscale dendritic needle network model of alloy solidification, Acta Mater. 61 (2013) 6474-6491.

[21] A. Karma, D. Tourret, Atomistic to continuum modeling of solidification microstructures, Curr. Opin. Solid State Mater. Sci. (2015) http://dx.doi.org/10.1016/j.cossms.2015.09.001. 
[22] L. Gránásy, L. Rátkai, A. Szállás, B. Korbuly, G.I. Tóth, L. Környei, T. Pusztai, Phase-Field Modeling of Polycrystalline Solidification: From Needle Crystals to Spherulites-A Review, Metall. Mater. Trans. A 45 (2014) 1694-1719.

[23] C-A Gandin, J-L Desbiolles, M. Rappaz, P. Thevoz, A three-dimensional cellular automaton-finite element model for the prediction of solidification grain structures, Metall. Mater. Trans. A 30 (1999) 3153-3165.

[24] M. Rappaz, Modeling and characterization of grain structures and defects in solidification, Curr. Opin. Solid State Mater. Sci. (2015) http://dx.doi.org/10.1016/j.cossms.2015.07.002.

[25] H.J. Fecht, B. Billia, ASM Handbook., in Metals Process Simulation, ed. D. Furrer, S.L. Semiatin, Vol. 22B. Materials Park: ASM International (2010).

[26] R. Trivedi, H. Miyahara, P. Mazumder, E. Simsek, S. N. Tewari, Directional solidification microstructures in diffusive and convective regimes, J. Cryst. Growth 222 (2001) 365-379.

[27] D. J. Jarvis, O. Minster, Metallurgy in Space, Materials Science Forum 508 (2006) 1-18.

[28] H. Nguyen-Thi et al., Investigation of gravity effects on solidification of binary alloys with in situ X-ray radiography on earth and in microgravity environment, Journal of Physics: Conference Series 327 (2011) 012012.

[29] A. Buffet, H. Nguyen Thi, A. Bogno, T. Schenk, N. Mangelinck-Noël, G. Reinhart, N. Bergeon, B. Billia, J. Baruchel, Measurement of solute profiles by means of synchrotron X-ray radiography during directional solidification of $\mathrm{Al}$ - 4 wt\% Cu alloys, Materials Science Forum 649 (2010) 331-336.

[30] P. Manneville, Dissipatives structures and weak turbulence, Academic Press, Boston (1990). 
[38] H. Esaka, W. Kurz, Columnar dendrite growth - experiments on tip growth, J. Cryst. Growth 72 (1985) 578-584.

[39] X. W. Qian, H. Z. Cummins, Dendritic sidebranching initiation by a localized heat pulse, Phys. Rev. Let. 64 (1990) 3038-3041.

1290

[31] A. Karma, A. Sarkissian, Morphological instabilities of lamellar eutectics, Met. Trans. A 27 (1996) 635-656.

[32] A. Dougherty, P.D. Kaplan, J.P. Gollub, Development of side branching in dendritic crystal-growth, Phys Rev. Lett. 58 (1987) 1652-1655. A. Dougherty, J. P. Gollub, Steady-state dendritic growth of HN4Br from solution, Phys. Rev. A 38 (1988) 3043-3053.

[33] L. Sallen, P. Oswald, J.C. Géminard, J. Malthète, Surface-tension and elasticity of hexagonal columnar mesophases, Journal de Physique II 5 (1995) 937-961.

[34] T. Börzsönyi, T. Tóth-Katona, Á. Buka, L. Gránásy, Regular dendritic patterns induced by nonlocal time-periodic forcing, Phys. Rev. E 62 (2000) 7817-7827.

[35] T. Börzsönyi, S. Akamatsu, G. Faivre, Dynamics of a faceted nematicsmectic B front in thin-sample directional solidification, Phys. Rev. E 65 (2002) 011702.

[36] J. C. La Combe, M. B. Koss, L. A. Tennenhouse, E. A. Winsa, M. E. Glicksman, The Clapeyron effect in succinonitrile: applications to crystal growth, J. Cryst. Growth 194 (1998) 143-148.

[37] H.M. Hawthorne, J.N. Sherwood, Lattice defects in plastic organic solids .1. self-diffusion and plastic deformation in pivalic acid, hexamethylethane and cyclohexane, Trans. Faraday Soc. 66 (1970) 1783-1791.

H. Jamgotchian, R. Trivedi, B. Billia, Array of doublets - a branch of cellular solutions in directional solidification, Phys. Rev. E 47 (1993) 43134322. 
[41] M. Georgelin, A. Pocheau, Onset of sidebranching in directional solidification, Phys. Rev. E 57 (1998) 3189-3203. M. Georgelin, A. Pocheau, Thermal gradient induced sidebranching in directional solidification, European Physical Journal B 4 (1998) 169-174.

[42] S. Akamatsu, S. Bottin-Rousseau, M. Perrut, G. Faivre, V.T. Witusiewicz, L. Sturz, Real-time study of thin and bulk eutectic growth in Succinonitrile(D)Camphor alloys, J. Cryst. Growth 299 (2007) 418-428.

[48] R. Trivedi, JT Mason, Eutectic spacing selection in lead-based alloy systems, Metal. Mater. Trans A 22 (1991) 235-249.

[49] P.E. Cladis, J.T. Gleeson, P.L. Finn, in Patterns and Instabilities, eds D. Walgraef and N. Ghoniem (Kluwer, Dordrecht, 1990). 
[50] H. Jamgotchian, R. Trivedi, B. Billia, Interface dynamics and coupled growth in directional solidification in presence of bubbles, J. Cryst. Growth 134 (1993) 181-195.

[51] S. Akamatsu, G. Faivre, Residual-impurity effects in directional solidification: Long-lasting recoil of the front and nucleation-growth of gas bubbles, J. Phys. I France 6 (1996) 503-527.

[52] S. Akamatsu, G. Faivre, T. Ihle, Symmetry-broken fingers and seaweed patterns in thin-film directional solidification of a non-faceted cubic crystal, Phys. Rev. E 51 (1995) 4751-4773.

[53] V.T. Witusiewicz, U. Hecht, S. Rex, M. Apel, In situ observation of microstructure evolution in low-melting Bi-In-Sn alloys by light microscopy, Acta Mater. 53 (2005) 3663-3669.

[54] W. Losert, B.Q. Shi, H.Z. Cummins, Evolution of dendritic patterns during alloy solidification: Onset of the initial instability, Proc. Nat. Acad. Sci. USA 95 (1998) 431-438. W. Losert, B.Q. Shi, H.Z. Cummins, Evolution of dendritic patterns during alloy solidification: From the initial instability to the steady state, Proc. Nat. Acad. Sci. USA 95 (1998) 439-442.

[55] V.G. Smith, W.A. Tiller, J.W. Rutter, A mathematical analysis of solute redistribution during solidification, Can. J. Phys. 33 (1955) 723-745. Also see W.A. Tiller, K.A. Jackson, J.W. Rutter, B. Chalmers, The redistribution of solute atoms during the solidification of metals, Acta Met. 1 (1953) 428-437.

[56] J.A. Warren, J.S. Langer, Prediction of dendritic spacings in a directionalsolidification experiment, Phys. Rev. E 47 (1993) 2702-2712.

[57] F. Lisboa-Mota, N. Bergeon, D. Tourret, A. Karma, R. Trivedi, B. Billia, Initial transient behavior in directional solidification of a bulk transparent model alloy in a cylinder, Acta Mater. 85 (2015) 362-377. 
[58] S. Bottin-Rousseau, M. Perrut, C. Picard, S. Akamatsu, G. Faivre, An experimental method for the in situ observation of eutectic growth patterns in bulk samples of transparent alloys, J. Cryst. Growth 306 (2007) 465-472.

[59] A. Ludwig, J. Mogeritsch, M. Kolbe, G. Zimmermann, L. Sturz, N. Bergeon, B. Billia, G. Faivre, S. Akamatsu, S. Bottin-Rousseau, D. Voss, Advanced Solidification Studies on Transparent Alloy Systems: A New European Solidification Insert for Material Science Glovebox on Board the International Space Station, JOM 64 (2012) 1097-1101.

[60] V. T. Witusiewicz, U. Hecht, S. Rex, Top-view approach for in- situ observation of growth morphology in bulk transparent organic alloys, J. Cryst. Growth 353 (2012) 17-24.

[61] V.T. Witusiewicz, U. Hecht, S. Rex, Fibrous eutectic growth in succinonitrile-neopentylglycol-(D)camphor-aminomethylpropanediol alloys for thin and bulk sample geometry, Acta Mater. 65 (2014) 360-372.

[62] N. Bergeon, A. Ramirez, L. Chen, B. Billia, J. Gu, R. Trivedi, Dynamics of interface pattern formation in 3D alloy solidification: first results from experiments in the DECLIC directional solidification insert on the International Space Station, J. Mater Sci. 46 (2011) 6191-6202.

[63] B. Kauerauf, G. Zimmermann, L. Murmann, S. Rex, Planar to cellular transition in the system succinonitrile-acetone during directional solidification of a bulk sample, J. Cryst. Growth 193 (1998) 701-711. B. Kauerauf, G. Zimmermann, S. Rex, M. Mathes, F. Grote, Directional cellular growth of succinonitrile-0.075 wt\% acetone bulk samples Part 1: Results of space experiments, J. Cryst. Growth 223 (2001) 265-276. B. Kauerauf, G. Zimmermann, S. Rex, B. Billia, H. Jamgotchian, J.D. Hunt, Directional cellular growth of succinonitrile- 0.075 wt\% acetone bulk samples Part 2: Analysis of cellular pattern, J. Cryst. Growth 223 (2001) 277-284.

[64] N. Bergeon, C. Weiss, N. Mangelinck-Noël, B. Billia, Interferometric 
method for the analysis of dendrite growth and shape in 3D extended patterns in transparent alloys, Trans. Indian Inst. Met. 62 (2009) 465-460.

[65] J.J. Favier, J.P. Garandet, A. Rouzaud, D. Camel, Mass-transport phenomena during solidification in microgravity - preliminary-results of the 1st Mephisto flight experiment, J. Crystal Growth 140 (1994) 237-243.

[66] J.P. Garandet, G. Boutet, P. Lehmann, B. Drevet, D. Camel, A. Rouzaud, J.J. Favier, G. Faivre, S. Coriell, J.I.D. Alexander, B. Billia, Morphological stability of a solid-liquid interface and cellular growth: Insights from thermoelectric measurements in microgravity experiments, J. Crystal Growth 279 (2005) 195-205.

[67] J. Alkemper, S. Sous, C. Stöcker, L Ratke, Directional solidification in an aerogel furnace with high resolution optical temperature measurements, J. Cryst. Growth 191 (1998) 252-260.

[68] P. Dold, M. Heidler, A. Drevermann, G. Zimmermann, In situ observation of growth interfaces by ultrasound, J. Cryst. Growth 256 (2003) 352-360.

[69] S. R. Coriell, G.B. McFadden, B. Billia, H. Nguyen Thi, Y. Dabo, Electrical pulsing during directional solidification: analysis of transients by Laplace transform, J. Cryst. Growth 216 (2000) 495-500.

[70] Y. Dabo, H. Nguyen Thi, S.R Coriell, G.B McFadden, Q. Li, B. Billia, Microsegregation in Peltier interface demarcation, J. Cryst. Growth 216 (2000) 483-494.

[71] G. Grange, C. Jourdan, J. Gastaldi, B. Billia, Stresses and defects in the formation of a cellular-pattern in directional solidification - Real-time observation by synchrotron $\mathrm{X}$-ray topography on a $\mathrm{Al}-0.73 w t-p e r c e n t ~ \mathrm{Cu}$ alloy, J. Phys. III France 4 (1994) 293-304.

[72] B. Billia, N. Bergeon, H. Nguyen Thi, H. Jamgotchian, J. Gastaldi, G. Grange, Cumulative mechanical moments and microstructure deformation 
induced by growth shape in columnar solidification, Phys. Rev. Lett. 93 (2004) 126105. H. Nguyen-Thi, G. Reinhart, N. Mangelinck-Noël, H. Jung, B. Billia, T. Schenk, J. Gastaldi, J. Hartwig, J. Baruchel, In-situ and real-time investigation of columnar-to-equiaxed transition in metallic alloy, Metal Mater Trans A 38A (2007) 1458-1464.

[73] A. Buffet, G. Reinhart, T. Schenk, H. Nguyen-Thi, J. Gastaldi, N. Mangelinck-Noël, H. Jung, J. Härtwig, J. Baruchel, B. Billia, Real-time and in situ solidification of Al-based alloys investigated by synchrotron radiation: a unique experimental set-up combining radiography and topography techniques, Phys. Status Solidi A 204 (2007) 2721-2727.

[74] G. Reinhart, A. Buffet, H. Nguyen-Thi, B. Billia, H. Jung, N. MangelinckNoël, N. Bergeon, T. Schenk, J. Härtwig, J. Baruchel, In-Situ and realtime analysis of the formation of strains and microstructure defects during solidification of Al-3.5 wt pct Ni alloys, Metall. Mater. Trans. A 39A (2008) $865-874$.

[75] A. Tandjaoui, N. Mangelinck-Noël, G. Reinhart, J.-J. Furter, B. Billia, T. Lafford, J. Baruchel, X. Guichard, Real time observation of the directional solidification of multicrystalline silicon: X-ray imaging characterization, Energy Proc. 27 (2012) 82-87.

[76] B.K. Tanner, D.K. Bowen (Eds), Characterization of Crystal Growth Defects by X-ray Methods, Plenum, New-York, 1980.

[77] G. Reinhart, et al, In Situ Investigation of Dendrite Deformation During Upward Solidification of Al-7wt.\%Si, JOM 66 (2014) 1408-1414.

[78] R.H. Mathiesen, L. Arnberg, K. Ramsoskar, T. Weitkamp, C. Rau, A. Snigirev, Time-resolved X-ray imaging of aluminum alloy solidification processes, Metall. Mater. Trans B 33 (2002) 613-623.

[79] R.H. Mathiesen, L. Arnberg, H. Nguyen Thi, B. Billia, In Situ X-Ray Video Microscopy as a Tool in Solidification Science, JOM 64 (2012) 76-82. 
[80] H. Yasuda, Direct Observation of stray crystal formation in unidirectional solidification of Sn-Bi alloy by X-ray imaging, J. Cryst. Growth 262 (2004) $645-652$

[81] H. Nguyen Thi, et al.,. Preliminary in situ and real-time study of directional solidification of metallic alloys by X-ray imaging techniques, J. Phys. D: Appl. Phys. 36 (2003) A83-A86.

[82] N. Limodin, L. Salvo, E. Boller, M. Suéry, M. Felberbaum, S. Gailliègue, K. Madi, In situ and real-time 3-D microtomography investigation of dendritic solidification in an Al-10 wt.\% Cu alloy, Acta Mater. 57 (2009) 2300-2310.

[83] L. Salvo, M. Suéry, A. Marmottant, N. Limodin, D. Bernard, 3D imaging in material science: Application of X-ray tomography, C. R. Phys. 11 (2010) 641-649.

[84] S. Terzi, J.A. Taylor, Y.H. Cho, L. Salvo, M. Suéry, E. Boller, A.K. Dahle, In situ study of nucleation and growth of the irregular alpha-Al/betaAl5FeSi eutectic by 3-D synchrotron X-ray microtomography, Acta Mater. 58 (2010) 5370-5380.

[85] S. Terzi, L. Salvo, M. Suéry, A.K. Dahle, E. Boller, Coarsening mechanisms in a dendritic Al-10\% Cu alloy, Acta Mater. 58 (2010) 20-30.

[86] R.H. Mathiesen, L. Arnberg, X-ray radiography observations of columnar dendritic growth and constitutional undercooling in an $\mathrm{Al}-30 \mathrm{wt} \% \mathrm{Cu}$ alloy, Acta Mater. 53 (2005) 947-956.

[87] G. Reinhart, et al., Investigation of columnar-equiaxed transition and equiaxed growth of aluminium based alloys by X-ray radiography, Materials Science and Engineering A 413 (2005) 384-388.

[88] H. Nguyen Thi, G. Reinhart, N. Mangelinck-Noël, H. Jung, B. Billia, T. Schenk, J. Gastaldi, J. Härtwig, J. Baruchel, In-Situ and Real-Time Investigation of Columnar to Equiaxed Transition in Metallic Alloy, Metall. Mater. Trans. A 38 (2007) 1458-1464. 
[89] H. Jung et al, Fragmentation in an Al-7wt\% Si alloy studied in real time by X-ray synchrotron techniques, Int. J. Cast. Metals Res. 1 (2009) 208-211.

[90] D. Ruvalcaba, R.H. Mathiesen, D.G. Eskin, L. Arnberg, L. Katgerman, In situ observations of dendritic fragmentation due to local solute-enrichment during directional solidification of an aluminum alloy, Acta Mat. 55 (2007) 4287-4292.

[91] H. Nguyen-Thi, L. Salvo, R. H. Mathiesen, L. Arnberg, B. Billia, M. Suéry, G. Reinhart, On the interest of synchrotron X-ray imaging for the study of solidification in metallic alloys, C.R. Physique 13 (2012) 237-245.

[92] A. Bogno, H. Nguyen-Thi, G. Reinhart, B. Billia, J. Baruchel, Growth and interaction of dendritic equiaxed grains: In situ characterization by synchrotron X-ray radiography, Acta Mat. 61 (2013) 1303-1315.

[93] A. Bogno, et al, Analysis by synchrotron X-ray radiography of convection effects on the dynamic evolution of the solid-liquid interface and on solute distribution during the initial transient of solidification, Acta Mat. 59 (2011) 4356-4365.

[94] N. Shevchenko, O. Roshchupkina, O. Sokolova, S. Eckert, The effect of natural and forced melt convection on dendritic solidification in Ga-In alloys, J. Cryst. Growth 417 (2015) 1-8.

[95] H. Nguyen-Thi, G. Reinhart, G. Salloum Abou Jaoude, R. H. Mathiesen, G. Zimmermann, Y. Houltz, D. Voss, A. Verga, D. J. Browne, A. G. Murphy, XRMON-GF: A novel facility for solidification of metallic alloys with in situ and time-resolved X-ray radiographic characterization in microgravity conditions, J. Cryst. Growth 374 (2013) 23-30.

[96] A. G. Murphy, J. Li, O. Janson, A. Verga, D. J. Browne, Microgravity and Hypergravity Observations of Equiaxed Solidification of Al-Cu Alloys Using In Situ X-Radiography Recorded in Real-Time on Board a Parabolic Flight, Materials Science Forum 790-791 (2014) 52-58. 
[104] N. Cabrera, The equilibrium of crystal surfaces, Surface Science 2 (1964) 320-345.

[105] M. Rappaz, J. Friedli, A. Mariaux, M. Salgado-Ordorica, The influence of solid-liquid interfacial energy anisotropy on equilibrium shapes, nucleation,

[97] M. Becker, C. Dreissgacker, S. Klein, F. Kargl, Near-isothermal furnace for in situ and real time X-ray radiography solidification experiments, Rev. Sci. Instrum. 86 (2015) 063904.

[98] G. P. Ivantsov, Temperature field around a spherical, cylindrical, and needle-shaped crystal, growing in a pre-cooled melt, Doklady Akad. Nauk. SSR 58 (1947) 567-569.

[99] A. Barbieri, J.S. Langer, Predictions of dendritic growth-rates in the linearized solvability theory, Phys. Rev. A 39 (1989) 5314-5325.

[100] A. Karma, W. J. Rappel, Quantitative phase-field modeling of dendritic growth in two and three dimensions, Phys. Rev. E 57 (1998) 4323-4349. W. J. Rappel, A. Karma, Phase-field model of dendritic sidebranching with thermal noise, Phys. Rev. E 60 (1999) 3614-3625.

[101] A. Karma, Y. H. Lee, M. Plapp, Three-dimensional dendrite-tip morphology at low undercooling Phys. Rev. E 61 (2000) 3996-4006.

[102] J. J. Hoyt, M. Asta, A. Karma, Method for computing the anisotropy of the solid-liquid interfacial free energy, Phys. Rev. Lett. 86 (2001) 5530-5533. J. J. Hoyt, M. Asta, A. Karma, Calculation of alloy solid-liquid interfacial free energies from atomic-scale simulations, Phys. Rev. B. 66 (2002) 100101.

[103] R.E. Napolitano, S. Liu, Three-dimensional crystal-melt Wulff-shape and interfacial stiffness in the Al-Sn binary system, Phys. Rev. B 70 (2004) 214103. triple lines and growth morphologies, Scripta Mat. 62 (2010) 904-909. 
[106] T. Ihle, H. Müller-Krumbhaar, Diffusion-limited fractal growthmorphology in thermodynamical 2-phase systems, Phys. Rev. Lett. 70 (1993) 3083-3086. T. Ihle, H. Müller-Krumbhaar, Fractal and compact growth morphologies in-phase transitions with diffusion transport, Phys. Rev. E 49 (1994) 2972-2991.

[107] R. Kupferman, D. A. Kessler, E. Ben-Jacob, Coexistence of symmetrical and parity-broken dendrites in a channel, Physica A 213 (1995) 451-464.

[108] M. Ben Amar, E. Brener, Parity-broken dendrites, Phys. Rev. Lett. 75 (1995) 561-564.

${ }_{1520}$ [109] R. Trivedi, Y.X. Shen, S Liu, Cellular-to-dendritic transition during the directional solidification of binary alloys, Metal. Mater. Trans. A 34 (2003) 395-401.

[110] B. Utter, R. Ragnarsson, E. Bodenschatz, Alternating tip splitting in directional solidification, Phys. Rev. Lett. 86 (2001) 4604-4607.

1525 [111] B. Utter, E. Bodenschatz, Dynamics of low anisotropy morphologies in directional solidification, Phys. Rev. E 66 (2002) 051604.

[112] H.M. Singer, J.H. Bilgram, Integral scaling behavior of different morphologies of 3D xenon crystals, Physica D 219 (2006) 101110.

[113] M.A. Salgado-Ordorica, J.L. Desbiolles, M. Rappaz, Study of the twinned 1530 dendrite tip shape I: Phase-field modeling, Acta Mater. 59 (2011) 50745084. M.A. Salgado-Ordorica, P. Burdet, M. Cantoni, M. Rappaz, Study of the twinned dendrite tip shape II: Experimental assessment, Acta Mater. 59 (2011) 5085-5091.

[114] M. Yang, S.M. Xiong, Z. Guo, Characterisation of the 3-D dendrite mor1535 phology of magnesium alloys using synchrotron X-ray tomography and 3-D phase-field modelling, Acta Mater. 92 (2015) 8-17. 
[115] S.K. Chan, H.H. Reimer, M. Kahlweit, Stationary growth shapes of NH4Cl dendrites, J. Cryst. Growth 32 (1976) 303-315.

[116] T. Haxhimali, A. Karma, F. Gonzales, M. Rappaz, Orientation selection in dendritic evolution, Nature Materials 5 (2006) 660-664.

[117] T. Ihle, Competition between kinetic and surface tension anisotropy in dendritic growth, Eur. Phys. J. B 16 (2000) 337-344.

[118] F. Celestini, J.M. Debierre, Measuring kinetic coefficients by molecular dynamics simulation of zone melting, Phys. Rev. E 65 (2002) 041605.

[119] J. Bragard, A. Karma, Y.H. Lee, M. Plapp, Linking phase-field and atomistic simulations to model dendritic solidification in highly undercooled melts, Interface Science 10 (2002) 121-136.

[120] Y. Saito, C. Misbah, H. Müller-Krumbhaar, Directional solidification transition from cells to dendrites, Phys. Rev. Lett. 63 (1989) 2377-2380.

[121] S. Gurevich, A. Karma, M. Plapp, R. Trivedi, Phase-field study of threedimensional steady-state growth shapes in directional solidification, Phys. Rev. E 81 (2010) 011603.

[122] S. Akamatsu, T. Ihle, Similarity law for the tilt angle of dendrites in directional solidification of non-axially-oriented crystals, Phys. Rev. E 56 (1997) 4479.

[123] J. Deschamps, M. Georgelin, A. Pocheau, Crystal anisotropy and growth directions in directional solidification Europhys. Lett. 76 (2006) 291-297. J. Deschamps, M. Georgelin, A. Pocheau, Growth directions of microstructures in directional solidification of crystalline materials, Phys. Rev. E 78 (2008) 011605.

[124] J. Ghmadh, J.M. Debierre, J. Deschamps, M. Georgelin, R. Guérin, A. Pocheau, Directional solidification of inclined structures in thin samples, Acta Mater. 74 (2014) 255267. 
[125] D. Tourret, A. Karma, Growth competition of columnar dendritic grains: A phase-field study, Acta Mater. 82 (2015) 64-83.

[126] K. Dragnevski, R. F. Cochrane, A. M. Mullis, Experimental evidence for dendrite tip splitting in deeply undercooled, ultrahigh purity $\mathrm{Cu}$, Phys. Rev. Lett. 89 (2002) 215502.

[127] J. Friedli, J.L. Fife, P. Di Napoli, M. Rappaz, Dendritic Growth Morphologies in Al-Zn Alloys-Part I: X-ray Tomographic Microscopy, Metal. Mater. Trans. A 44A (2013) 5522-5531.

[128] A. Wagner, B.A. Shollock, M. McLean, Grain structure development in directional solidification of nickel-base superalloys, Materials Science Eng. A 374 (2004) 270-279.

1575

[129] M. Rappaz, C.A. Gandin, J.L. Desbiolles, P. Thévoz, Prediction of Grain Structures in Various Solidification Processes, Metall. Mater. Trans. A 27A (1996) 695-705.

[130] Y. Shibuta, M. Ohno, T. Takaki, Solidification in a Supercomputer: From Crystal Nuclei to Dendrite Assemblages, JOM 67 (2015) 1793-1804.

[131] J. S. Langer, Dendritic sidebranching in the 3-dimensional symmetrical model in the presence of noise, Phys. Rev. A 36 (1987) 3350.

[132] A. Classen, C. Misbah, H. Müller-Krumbhaar, Y. Saito, Directional solidification with interface dissipation, Phys. Rev. A 43 (1991) 6920-6933.

[133] A. Pocheau, S. Bodea, M. Georgelin, Self-organized dendritic sidebranching in directional solidification: Sidebranch coherence within uncorrelated bursts, Phys. Rev. E 80 (2009) 031601.

[134] B. Echebarria, A. Karma, S. Gurevitch, Onset of sidebranching in directional solidification, Phys. Rev. E 81 (2010) 021608.

[135] P. Bouissou, B. Perrin, P. Tabeling, Influence of an external flow on dendritic crystal-growth, Phys. Rev. A 40 (1989) 509-512. P. Bouissou, A. 
Chiffaudel, B. Perrin, P. Tabeling, Dendritic side-branching forced by an external flow, Europhys. Lett. 13 (1990) 89-94.

[136] M.E. Glicksman, Mechanism of Dendritic Branching, Metal. Mater. Trans. A 43A (2012) 391-404. M.E. Glicksman, Capillary-mediated dendritic branching, IOP Conf. Series: Materials Science and Engineering 33 (2012) 012097. Also see: A. Mullis, Deterministic side-branching during thermal dendritic growth, IOP Conf. Series: Materials Science and Engineering 84 (2015) 012071.

[137] Y. Couder, J. Maurer, R. González-Cinca, A. Hernández-Machado, Sidebranch growth in two-dimensional dendrites. I. Experiments, Phys. Rev. E 71 (2005) 031602.

[138] R. Trivedi, V. Seetharaman, M. A. Eshelman, The effects of interface kinetics anisotropy on the growth direction of cellular microstructures, Metall. Trans. A 22A (1991) 585-593.

[139] J. T. Gleeson, P. Cladis, Traveling-wave states in deep-groove directional solidification, Phys. Rev. Lett. 66 (1991) 236-239.

[140] S. de Cheveigné, C. Guthmann, Interface dynamics and anisotropy effects in directional solidification, J. Physique I 2 (1992) 193-205.

[141] S. Akamatsu, G. Faivre, Anisotropy-driven dynamics of cellular fronts in directional solidification in thin samples, Phys. Rev. E 58 (1998) 3302-3315.

[142] M. Georgelin, A. Pocheau, Oscillatory instability, limit cycle, and transition to doublets in directional solidification, Phys. Rev. Lett. 79 (1997) 2698-2701.

[143] W. Losert, D. A. Stillman, H. Z. Cummins, P. Kopczynski, W.-J. Rappel, A. Karma, Selection of doublet cellular patterns in directional solidification through spatially periodic perturbations, Phys. Rev. E 58 (1998) 7492-7506. 
[144] P. Kopczynski, W-J. Rappel, A. Karma, Critical role of crystalline anisotropy in the stability of cellular array structures in directional solidification, Phys. Rev. Lett. 77 (1996) 3387-3390.

[145] M. Georgelin, A. Pocheau, Characterization of cell tip curvature in directional solidification, J. Cryst. Growth. 268 (2004) 272-283.

[146] W. Huang, X. Geng, Y. Zhou, Primary spacing selection of constrained dendritic growth, J. Cryst. Growth 134 (1993) 105-115.

[147] W. Losert, O. N. Mesquita, J. M. A. Figueiredo, H. Z. Cummins, Direct measurement of dendritic array stability, Phys. Rev. Lett. 81 (1998) 409412.

[148] R. Kikuchi, J.R. Cahn, Grain-boundary melting transition in a twodimensional lattice-gas model, Phys. Rev. B 21 (1980) 1893-1897.

[149] S. Bottin-Rousseau, S. Akamatsu, G. Faivre, Dynamical polygonization below the cellular-bifurcation threshold in thin-sample directional solidification, Phys. Rev. B 66 (2002) 054102.

[150] R.J. Schaefer, M.E. Glicksman, J.D. Ayers, High-confidence measurement of solid-liquid surface-energy in a pure material, Philos. Mag. 32 (1975) 725-743.

[151] U. Boeyuek, S. Engin, N. Marasli, Novel experimental technique to observe equilibrated grain boundary groove shapes in opaque alloys, Journal of Alloys and Compounds 476 (2009) 213-219.

[152] R.B. Rogers, R.J. Ackerson, The measurement of solid-liquid interfacial energy in colloidal suspensions using grain boundary grooves, Phil. Mag. 91 (2011) 682729.

[153] H. Akita, D.S. Sampar, N.F. Fiore, Substructure control by solidification control in Cu crystals, Met. Trans. 4 (1973) 1593-1597. 
[154] G. Faivre, S. Bottin-Rousseau, S. Akamatsu, The trajectory of subboundary grooves during directional solidification of dilute alloy, C. R. Physique 14 (2013) 149-155.

[155] A. J. Pons, A. Karma, S. Akamatsu, M. Newey, A. Pomerance, H. Singer, W. Losert, Feedback control of unstable cellular solidification fronts, Phys. Rev. E 75 (2007) 021602.

[156] S. Akamatsu, K. Y. Lee, W. Losert, Control of eutectic solidification microstructures through laser spot perturbations, J. Cryst. Growth 289 (2006) 331-338.

[157] K. Lee, W. Losert, Controlled dynamics of grain boundaries in binary alloys, Acta Mater. 53 (2005) 3503-3510.

[158] M.E. Glicksman, R.J. Schaefer, J.D. Ayers, Dendritic growth - Test of theory, Metal. Mater. Trans A 7A (1976) 1747-1759.

[159] L.A. Tennenhouse, M.B. Koss, J.C. LaCombe, M.E. Glicksman, Use of microgravity to interpret dendritic growth kinetics at small supercoolings, J. Cryst. Growth 174 (1997) 82-89.

[160] J.C. LaCombe, M.B. Koss, V. E. Fradkov, M.E. Glicksman, 3-dimensional dendrite-tip morphology, Phys. Rev. E 52 (1995) 2778-2786.

[161] M.B. Koss, J.C. LaCombe, L.A. Tennenhouse, M.E. Glicksman, E.A. Winsa, Dendritic growth tip velocities and radii of curvature in microgravity, Metall. Mater. Trans. A 30 (1999) 3177-3190.

[162] M.E. Glicksman, A.O. Lupulescu, Dendritic crystal growth in pure materials, J. Cryst. Growth 264 (2004) 541-549.

[163] V. Pines, A. Chait, M. Zlatkowski, Thermal diffusion dominated dendritic growth: an analysis of the wall proximity effect, J. Cryst. Growth 167 (1996) 383-386. 
[164] Q. Li, C. Beckermann, Scaling behavior of three-dimensional dendrites, Phys. Rev. E 57 (1998) 3176-3188.

[165] A. Badillo, D. Ceynar, C. Beckermann, Growth of equiaxed dendritic crystals settling in an undercooled melt, Part 1: Tip kinetics, J. Cryst. Growth 309 (2007) 197-215. A. Badillo, D. Ceynar, C. Beckermann, Growth of equiaxed dendritic crystals settling in an undercooled melt, Part 2: Internal solid fraction, J. Cryst. Growth 309 (2007) 216-215.

[166] Q. Li, C. Beckermann, Modeling of free dendritic growth of succinonitrileacetone alloys with thermosolutal melt convection, J. Cryst. Growth 236 (2002) 482-498.

[167] S. Gerardin, H. Combeau, G. Lesoult, Effect of relative crystal-liquid movement on the growth of a dendritic crystal in a supercooled liquid, Journal de Physique IV 11 (2001) 143-150.

[168] H. M. Singer, J. H. Bilgram, Three-dimensional reconstruction of xenon dendrites, Europhys. Lett. 68 (2004) 240-246.

[169] H. Singer, I. Singer-Loginova, J. Bilgram, G. Amberg, Morphology diagram of thermal dendritic solidification by means of phase-field models in two and three dimensions, J. Cryst. Growth 296 (2006) 58-68.

[170] A.J. Melendez, C. Beckermann, Measurements of dendrite tip growth and sidebranching in succinonitrile-acetone alloy, J. Cryst. Growth 340 (2012) 175-189.

[171] E. Brener, Needle-crystal solution in three-dimensional dendritic growth, Phys. Rev. Lett. 71 (1993) 3653-3656.

[172] M.D. Dupouy, D. Camel, J.J. Favier, Natural Convective Effects in Directional Dendritic Solidification of Binary Metallic Alloys - Dendritic Array Primary Spacing, Acta. Mater. 40 (1992) 1791-1801. M.D. Dupouy, D. Camel, J-J Favier, Natural convection in directional dendritic solidification 
of metallic alloys: I. Macroscopic effects., Acta Metall. 37 (1989) 11431157. M.D. Dupouy, D. Camel, J-J Favier, Natural convective effects in directional dendritic solidification of binary metallic alloys: dendritic array morphology, J. Cryst. Growth 126 (1993) 480-492.

[178] K. Kassner, J.M. Debierre, B. Billia, N. Noël, H. Jamgotchian, Cellular structures in three-dimensional directional solidification: Simulation and analysis, Phys. Rev. E 57 (1998) 2849-2861. 
[179] M. Plapp, M. Dejmek, Stability of hexagonal solidification patterns, Europhys. Lett. 65 (2004) 276-282.

[180] S. Bottin-Rousseau, A. Pocheau, Self-Organized Dynamics on a Curved Growth Interface, Phys. Rev. Lett. 87 (2001) 076101.

[181] H. Jamgotchian, N. Bergeon, D. Benielli, P. Voge, B. Billia, R. Guérin, Localized Microstructures Induced by Fluid Flow in Directional Solidification, Phys. Rev. Lett. 87 (2001) 166105.

[182] J.A. Spittle, Columnar to equiaxed grain transition in as solidified alloys, Int. Mater. Rev. 51 (2006) 247-269.

[183] K.A. Jackson, J.D. Hunt, D.R. Uhlmann, T.P. Seward, On the origin of the Equiaxed Zone in Castings, Trans. Metal. Soc. AIME 236 (1966) $149-158$.

[184] M. H. Johnston, C. S. Griner, Direct Observation of Solidification as a Function of Gravity Level, Metal. Trans. A 8 (1977) 77-82. M. H. Johnston, C. S. Griner, R. A. Parr, S. J. Robertson, The Direct Observation of Unidirectional Solidification as a Function of Gravity Level, J. Cryst. Growth 50 (1980) 831-838.

[185] C. J. Paradies, R. N. Smith, M. E. Glicksman, The influence of convection during solidification on fragmentation of the mushy zone of a model alloy, Metall. Mater. Trans. A 28 (1997) 875-883.

[186] S. Liu, S.Z. Lu, A. Hellawell, Dendritic array growth in the systems $\mathrm{NH} 4 \mathrm{Cl}-\mathrm{H} 2 \mathrm{O}$ and $[\mathrm{CH} 2 \mathrm{CN}] 2-\mathrm{H} 2 \mathrm{O}$ : the detachment of dendrite side arms induced by deceleration, J. Cryst. Growth 234 (2002) 740-750.

[187] G. Salloum-Abou-Jaoude, H. Nguyen-Thi, G. Reinhart, R. H. Mathiesen, G. Zimmermann, D. Voss, Characterization of motion of dendrite fragment by X-ray radiography on Earth and under microgravity environment, Mater. Sci. Forum 790-791 (2014) 311-316. 
[188] Y. Sun, C. Beckermann, Effect of solid-liquid density change on dendrite tip velocity and shape selection, J. Cryst. Growth 311 (2009) 4447-4453.

[189] W. K. Burton, N. Cabrera, F. C. Frank, The Growth of Crystals and the Equilibrium Structure of their Surfaces, Phil. Roy. Soc. London 243 (1951) 299-358.

[190] K.A. Jackson, Liquid metals and Solidification, in Growth and perfection of crystals, eds R.H. Doremus, B.W. Roberts, D. Turnbull, Wiley, New York (1958).

[191] J. Maurer, P. Bouissou, B. Perrin, P. Tabeling, Faceted dendrites in the growth of nh4br crystals, Europhys. Lett. 8 (1989) 67-72.

[192] M. Adda Bedia, M. Ben Amar, Faceting in free dendritic growth, Phys. Rev. E 51 (1995) 1268-1275.

[193] J.M. Debierre, A. Karma, F. Celestini, R. Guérin, Phase-field approach for faceted solidification, Phys. Rev. E 68 (2003) 041604.

[194] T. Börzsönyi, S. Akamatsu, G. Faivre, Weakly faceted cellular patterns versus growth-induced plastic deformation in thin-sample directional solidification of monoclinic biphenyl, Phys. Rev. E 80 (2009) 051601.

[195] Y. Dabo, H. Nguyen Thi, S.R. Coriell, G.B. McFadden, Q. Li, B. Billia, Microsegregation in Peltier interface demarcation, J. Cryst. Growth 216 (2000) 483-494.

[196] K. Fujiwara, K. Maeda, N. Usami, G. Sazaki, Y. Nose, A. Nomura, T. Shishido, K. Nakajima, In situ observation of Si faceted dendrite growth from low-degree-of-undercooling melts, Acta Mater. 56 (2008) 2663-2668.

[197] T. Riberi-Beridot, N. Mangelinck-Noël, A. Tandjaoui, G. Reinhart, B. Billia, T. Lafford, J. Baruchel, L. Barrallier, On the impact of twinning on the formation of the grain structure of multi-crystalline silicon for photovoltaic 
applications during directional solidification, J. Cryst. Growth 418 (2015) $38-44$.

[198] A. Tandjaoui, N. Mangelinck-Noël, G. Reinhart, B. Billia, T. Lafford, J. Baruchel, Investigation of grain boundary grooves at the solid-liquid interface during directional solidification of multi-crystalline silicon: in situ characterization by X-ray imaging, J. Cryst. Growth 377 (2013) 203-211.

[199] E. Yokoyama, I. Yoshizaki, T. Shimaoka, T. Sone, T. Kiyota, Y. Furukawa, Measurements of Growth Rates of an Ice Crystal from Supercooled Heavy Water under Microgravity Conditions: Basal Face Growth Rate and Tip Velocity of a Dendrite, J. Phys. Chem. B 115 (2011) 8739-8745.

[200] Y. Teraoka, A. Saito, S. Okawa, Ice crystal growth in supercooled solution, International Journal of Refrigeration 25 (2002) 218-225.

[201] T. Fujioka, R. F. Sekerka, Morphological stability of disc crystals, J. Cryst. Growth 24/25 (1974) 84-93.

[202] D.A. Pawlak, K. Kolodziejak, K. Rozniatowski, R. Diduszko, M. Kaczkan, M. Malinowski, M. Piersa, J. Kisielewski, T. Lukasiewicz, PrAlO3PrAl11O18 Eutectic: Its Microstructure and Spectroscopic Properties, Crystal Growth \& Design 8 (2008) 1243-1249.

[203] S. Akamatsu, M. Plapp, Eutectic and peritectic solidification patterns, Curr. Opin. Solid State Mater. Sci. (2015) http://dx. doi.org/10.1016/j.cossms.2015.10.002.

[204] M. Hillert, Role of interfacial energy during solidstate phase transformations, Jernkontorets Ann. 141 (1957) 757-789.

[205] K. Kassner, C. Misbah, Growth of lamellar eutectic structures - the axisymmetrical state, Phys. Rev. A 44 (1991) 6513-6533.

[206] K. Somboonsuk, J.T. Mason, R. Trivedi, Interdendritic spacing: 1.Experimental studies, Metall. Trans. A 15A (1984) 967-975. 
[207] S. de Cheveigné, G. Faivre, C. Guthmann, P. Kurowski, Directional solid-

[212] J. S. Langer, Eutectic solidification and marginal stability, Phys. Rev. Lett. 44 (1980) 1023-1026.

[213] W. Datye, J.S. Langer, Stability of thin lamellar eutectic growth, Phys.

[214] S. Akamatsu, M. Plapp, G. Faivre, A. Karma, Pattern stability and trijunction motion in eutectic solidification, Phys. Rev. E 66 (2002) 030501(R).

[215] S. Akamatsu, M. Plapp, G. Faivre, A. Karma, Overstability of lamellar 1830 Structures in Dissipative Continuous Systems, eds. F.H. Busse, L. Kramer, Plenum Press, New York (1990) 445-448.

[208] G. Faivre, J. Mergy, Tilt bifurcation and dynamic selection by tilt domains in thin-film lamellar eutectic growth - experimental-evidence of a tilt bifurcation, Phys. Rev. A 45 (1992) 7320-7329. G. Faivre, J. Mergy, Dynamic wavelength selection by tilt domains in thin-film lamellar eutectic growth, Phys. Rev. A 46 (1992) 963-972.

[209] M. Ginibre, S. Akamatsu, G. Faivre, Experimental determination of the stability diagram of a lamellar eutectic growth front, Phys. Rev. E 56 (1997) 780-796.

[210] V.T. Witusiewicz, L. Sturz, U. Hecht, S. Rex, Lamellar coupled growth in the neopentylglycol-(D)camphor eutectic, J. Crystal Growth 386 (2011) 69-75.

[211] S. Akamatsu, S. Bottin-Rousseau, G. Faivre, Determination of the Jackson-Hunt constants of the In-In2Bi eutectic alloy based on in situ observation of its solidification dynamics, Acta Mater. 59 (2011) 7586-7591. eutectic growth below the minimum-undercooling spacing, Metal. Mater. Trans. A 35 (2004) 1815-1828. 
[216] V.T. Witusiewicz, U. Hecht, S. Rex, In-situ observation of eutectic growth in Al-based alloys by light microscopy, J. Crystal Growth 372 (2013) 57-64.

[217] A. Karma, A. Sarkissian, Morphological instabilities of lamellar eutectics, Met. Trans. A 27 (1996) 635-656.

[218] C. T. Rios, S. Milenkovic, R. Caram, A novel ternary eutectic in the NbAlNi system, Scripta Mater. 48 (2003) 1495-1500.

[219] M. Rinaldi, R. Sharp, M. Flemings, Growth of ternary composites from melt: Part I, Metall. Trans. 3 (1972) 3133-3138.

[220] S. Akamatsu, G. Faivre, Traveling waves, two-phase fingers, and eutectic colonies in thin-sample directional solidification of a ternary eutectic alloy, Phys. Rev. E 61 (2000) 3757-3770.

[221] M. Plapp, A. Karma, Eutectic colony formation: A stability analysis, Phys. Rev. E 60 (1999) 6865-6889. M. Plapp, A. Karma, Eutectic colony formation: A phase-field study, Phys. Rev. E 66 (2002) 061608.

[222] G. Boussinot, C. Hueter, E. A. Brener, Growth of a two-phase finger in eutectics systems, Phys. Rev. E 83 (2011) 020601.

[223] Z. Shang, J. Shen, J. Zhang, L. Wang, L. Wang, H. Fu, Effect of microstructures on the room temperature fracture toughness of NiAl-32Cr6 Mo hypereutectic alloy directionally solidified at different withdrawal rates, Mater. Sci. Eng. A 611 (2014) 306-312.

[224] P. Fehrenbach, H. Kerr, P. Niessen, Unidirectional solidification of monovariant $\mathrm{Cu}-\mathrm{Ni}-\mathrm{Mg}$ eutectic alloys. 2. Microstructures and properties, J. Cryst. Growth 18 (1973) 151-158.

1855 [225] U. Hecht, V.T. Witusiewicz, A. Drevermann, S. Rex, Orientation relationship in univariant Al-Cu-Ag eutectics, Trans. Indian Inst. Met. 58 (2005) 545-551. 
[226] S. Tewari, S. Raj, I. Locci, A comparison between growth morphology of eutectic cells/dendrites and single-phase cells/dendrites, Metal. Mater. Trans A 35A (2004) 1632-1635.

[227] S. Akamatsu, M. Perrut, S. Bottin-Rousseau, G. Faivre, Spiral two-phase dendrites, Phys. Rev. Lett. 104 (2010) 056101.

[228] S. Akamatsu, S. Bottin-Rousseau, G. Faivre, E.A. Brener, Scaling theory of two-phase dendrites, Phys. Rev. Lett. 112 (2014) 105502.

[229] T. Pusztai, L. Rátkai, A. Szállás, L. Gránásy, Spiraling eutectic dendrites, Phys. Rev. E 87 (2013) 032401.

[230] L. Rátkai, A. Szállás, T. Pusztai, T. Mohri, L. Gránásy, Ternary eutectic dendrites: Pattern formation and scaling properties, J. Chem. Phys. 142 (2015) 154501.

[231] T. Himemiya, T. Umeda, Three-phase planar eutectic growth models for a ternary eutectic system, Mater. T. JIM 40 (1999) 665-674.

[232] A. Choudhury, M. Plapp, B. Nestler, Theoretical and numerical study of lamellar eutectic three-phase growth in ternary alloys, Phys. Rev. E 83 (2011) 051608.

[233] V.T. Witusiewicz, L. Sturz, U. Hecht, S. Rex, Phase equilibria and eutectic growth in quaternary organic alloys amino-methylpropanediol-(D)camphor-neopentylglycol-succinonitrile (AMPD-DC-NPGSCN), J. Cryst. Growth 297 (2006) 117-132.

[234] S. Bottin-Rousseau, private communication.

[235] M. Ruggiero, J. Rutter, Origin of microstructure in the $332 \mathrm{~K}$ eutectic of the Bi-In-Sn system, Mater. Sci. Tech. Ser. 13 (1997) 5-11.

[236] A. Genau, L. Ratke, Morphological characterization of the Al-Ag-Cu ternary eutectic, Int. J. Mater. Res. 103 (2012) 469-475. 
[237] R. J. Contieri, C. T. Rios, M. Zanotello, R. Caram, Growth and three-

[238] L.M. Hogan, R.W. Kraft, F.D. Lemkey, Eutectic grains, Adv. Mater. Res. 5 (1971) 83.

[239] U. Hecht, L. Granasy, T. Pusztai , B. Böttger, M. Apel, V. Witusiewicz,

[244] V. Kokotin, U. Hecht, Molecular dynamics simulations of Al-Al2Cu phase boundaries, Comp. Mater. Sci. 86 (2014) 30-37.

[245] S. Akamatsu, S. Bottin-Rousseau, G. Faivre, Experimental evidence for a zigzag bifurcation in bulk lamellar eutectic growth, Phys. Rev. Lett. 93 (2004) 175701. 
[246] A. Karma, M. Plapp, New Insights into the Morphological Stability of Eutectic and Peritectic Coupled Growth, JOM 56 (2004) 28-32.

[247] A. Parisi, M. Plapp, Stability of lamellar eutectic growth, Acta Mater. 56 (2008) 1348-1357.

[248] H. Walker, S. Liu, J. H. Lee, R. Trivedi, Eutectic growth in three dimen-

[249] A. Parisi, M. Plapp, Defects and multistability in eutectic solidification patterns, EPL 90 (2010) 26010.

[250] M. Perrut, A. Parisi, S. Akamatsu, S. Bottin-Rousseau, G. Faivre, M. Plapp, Role of transverse temperature gradients in the generation of lamel-

[251] M. Şerefoğlu, S. Bottin-Rousseau, S. Akamatsu, G. Faivre, Dynamics of rod eutectic growth patterns in confined geometry, IOP Conference SeriesMaterials Science and Engineering 27 (2012) 012030.

[252] M. Perrut, S. Akamatsu, S. Bottin-Rousseau, G. Faivre, Long-time dynamics of the directional solidification of rodlike eutectics, Phys. Rev. E 79 (2009) 032602.

[253] M. Perrut, S. Bottin-Rousseau, G. Faivre, S. Akamatsu, Dynamic instabilities of rod-like eutectic growth patterns: A real-time study, Acta Mater. 61 (2013) 6802-6808.

[254] R. E. Napolitano, M. Şerefoğlu, Control and Interpretation of Finite-Size Effects and Initial Morphology in Directional Solidification of a Rod-Type Eutectic Transparent Metal-Analog, JOM 64 (2012) 68-75.

[255] V. Trnovcova, P.P. Fedorov, C. Barta, V. Labas, V.A. Meleshina, B.P. Sobolev, Microstructure and physical properties of superionic eutectic com1935 posites of the LiF-RF3 ( $\mathrm{R}=$ rare earth element) system, Solid State Ionics 119 (1999) 173-180. 
[256] S. Liu, J. H. Lee, R. Trivedi, Dynamic effects in the lamellar-rod eutectic transition, Acta Mater. 59 (2011) 3102-3115.

[257] L. Ratke, J. Alkemper, Ordering of the fibrous eutectic microstructure of Al-Al3Ni due to accelerated solidification conditions, Acta Mater. 48 (2000) 1939-1948.

[258] R. Racek, G. Lesoult, M. Turpin, Cd-Sn Eutectic Structures at Low Growth-rates, J. Cryst. Growth 22 (1974) 210-218.

[259] S. Liu, A. Hellawell, Experiments with constrained chimney-plume flows in the system ammonium chlorid-water: comparison with the unconstrained case, J. Fluid Mech. 388 (1999) 21-48.

[260] T. Jiang, M. Georgelin, A. Pocheau, Flow-induced traveling waves on solidification interfaces, EPL 102 (2013) 54002.

[261] O. Funke, G. Phanikumar, P.K. Galenko, L. Chernova, S. Reutzel, M. Kolbe, D.M. Herlach, Dendrite growth velocity in levitated undercooled nickel melts, J. Cryst. Growth 297 (2006) 211-222.

[262] A. Chiocca, F. Soulie, F. Deschaux-Beaume, C. Bordreuil, In-situ observation and modelling of solidification and fluid flow on GTAW proces, IOP Conference Series-Materials Science and Engineering 84 (2015) 012028.

[263] R. Trivedi, S. A. David, M. A. Eshelman, J. M. Vitek, S. S. Babu, T. Hong, T. DebRoy, In situ observations of weld pool solidification using transparent metal-analog systems, J. Appl. Phys. 93 (2003) 4885-4895.

[264] J. Fonseca, C. O'Sullivan, T. Nagira, H. Yasuda, C. Gourlay, In situ study of granular micromechanics in semi-solid carbon steels, Acta Mater. 61 1960 (2013) 4169-4179.

[265] T. Subroto, A. Miroux, L. Bouffier, C. Josserond, L. Salvo, M. Suéry, D.G. Eskin, L. Katgerman, Formation of Hot Tear Under Controlled Solidification Conditions, Metal. Mater. Trans. A 45A (2014) 2855-2862. 
[266] J. W. Gibbs, K. A. Mohan, E. B. Gulsoy, A. J. Shahani, X. Xiao, C. A.

Bouman, M. De Graef, P. W. Voorhees, The Three-Dimensional Morphology of Growing Dendrites, Scientific Reports 5 (2015) 11824.

[267] W. F. Kaukler, F. Rosenberger, P. A. C., In Situ Studies of Precipitate Formation in Al-Pb Monotectic Solidification by X-Ray Transmission Microscopy, Metalll. Mater. Trans. A 28A (1997) 1705-1710.

[268] U.S. Rai, R.N. Rai, Physical chemistry of the organic analog of metalmetal eutectic and monotectic alloys, J. Cryst. Growth 191 (1998) 234-242.

[269] I. Farup, J.M. Drezet, M. Rappaz, In situ observation of hot tearing formation in succinonitrile-acetone, Acta Mater. 49 (2001) 1261-1269.

[270] M. C. Cox, A.V. Anilkumar, R. N. Grugel, C. P. Lee, Effect of step-wise change in processing pressure on isolated pore growth during controlled directional solidification in small channels, J. Cryst. Growth 311 (2009) 327-336.

[271] S. Griesser, M. Reid, C. Bernhard, R. Dippenaar, Diffusional constrained crystal nucleation during peritectic phase transitions, Acta Mater. 67 (2014) 335-341.

[272] S. S. L. Peppin, M. Grae Worster, J.S. Wettlaufer, Morphological instability in freezing colloidal suspensions, Proc. R. Soc. A 463 (2007) 723-733.

[273] A.P. Gast, Y. Monovoukas, A new growth instability in colloidal crystallization, Nature 351 (1991) 553-555.

[274] J. Zhu, M. Li, R. Rogers, W. Meyer, R. H. Ottewill, W. B. Russel, P. M. Chaikin, Crystallization of hard-sphere colloids in microgravity, Nature 387 (1997) 883-885.

[275] C. De Rosa, C. Park, E.L. Thomas, B. Lotz, Microdomain patterns from directional eutectic solidification and epitaxy, Nature 405 (2000) 433-437. 
[276] B.C. Okerberg, H. Marand, J. F. Douglas, Dendritic crystallization in thin films of PEO/PMMA blends: A comparison to crystallization in small molecule liquids, Polymer 49 (2008) 579-587.

[277] S. Akamatsu, O. Bouloussa, K. To, F. Rondelez, Two-dimensional dendritic growth in Langmuir monolayers of D-Myristoyl Alanine, Phys. Rev.

[282] A.J. Shahani, E.B. Gulsoy, V.J. Roussochatzakis, J.W. Gibbs, J.L. Fife, P.W. Voorhees, The dynamics of coarsening in highly anisotropic systems: Si particles in Al-Si liquids, Acta Mater. 97 (2015) 325-337. 